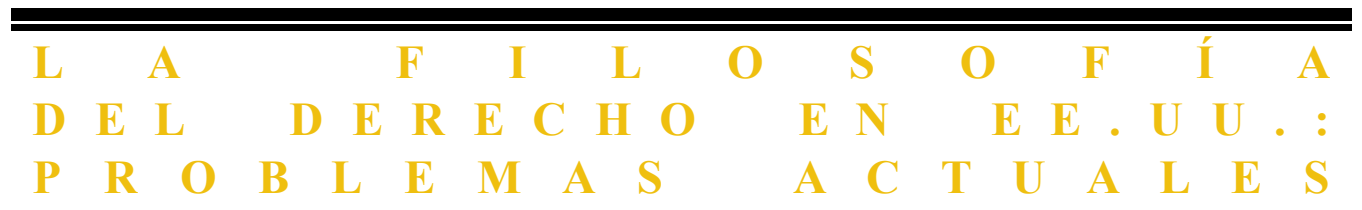




\section{LA ENSEÑANZA DEL DERECHO EN ESTADOS UNIDOS}

\section{Introducción}

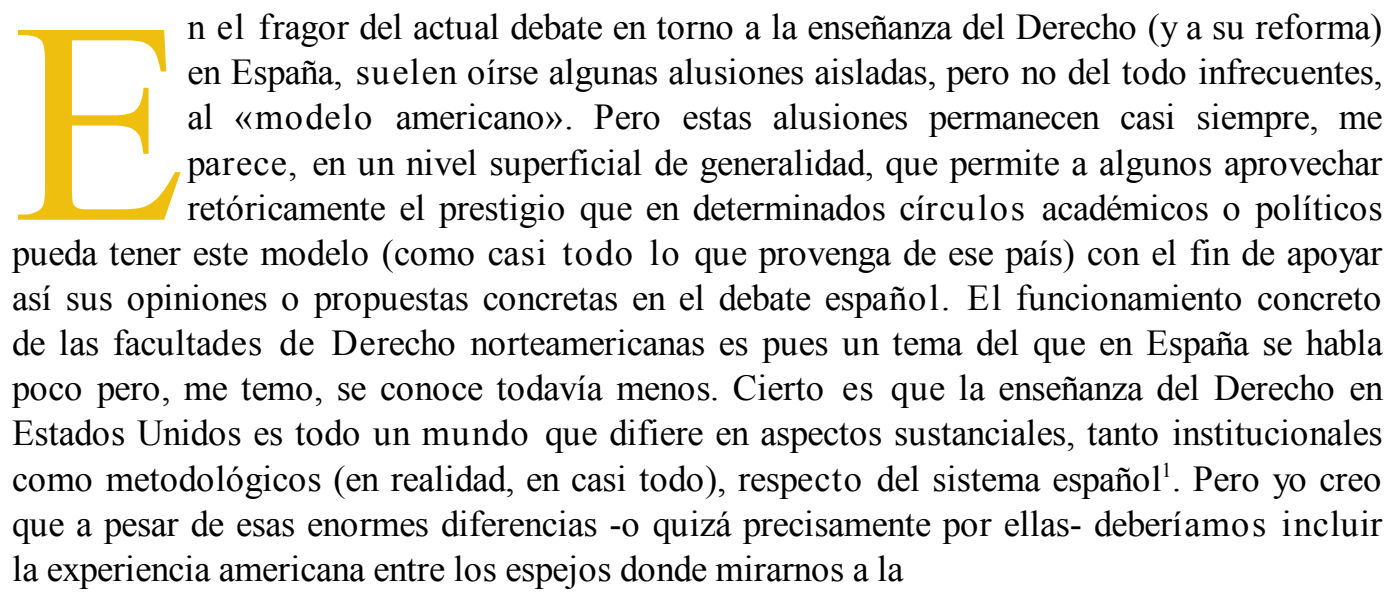

${ }^{1}$ Esta afirmación parece obvia: cualquier jurista español que no esté familiarizado con el sistema educativo americano podría aventurarla, dado que se trata de un país perteneciente a la familia del Common Law. Aun así, ese mismo lector quizá todavía se sorprenda un poco al ver hasta qué extremo llegan esas diferencias. Incluso son casi igualmente notables las diferencias que separan en este tema (como en muchos otros) a Estados Unidos del otro gran país (y padre) de esta "familia», Inglaterra. Para un breve estudio comparativo entre estos dos países, véase el capítulo correspondiente a la enseñanza del Derecho en Atiyah, P.S.; Summers, R.S., Form and Substance in Anglo-American Law, Clarendon, Oxford, 1987 (cap. 14, pp. 384-407). Seguiré este texto en bastantes aspectos de mi trabajo: muchas de las peculiaridades del sistema americano destacadas por estos autores en su comparación con Inglaterra son igualmente aplicables a una comparación con España. 
hora de hacer el diagnóstico y emprender la transformación de la enseñanza del Derecho en España. De los logros alcanzados y de los errores cometidos en Estados Unidos podemos aprender por lo menos tanto como de la situación en otros países más próximos en los que tradicionalmente tendemos a fijarnos mucho más. Sobre todo, podríamos aprender cosas distintas de un sistema tan distinto $^{2}$.

El objetivo de este trabajo es pues suministrar una cierta información básica acerca de la enseñanza del Derecho en Estados Unidos. No puedo extenderme en un estudio a fondo de este tema, que allí constituye toda una subdisciplina jurídica («Legal Education») enormemente desarrollada ${ }^{3}$. Pero al menos me detendré en algunas líneas generales acerca del estudio del Derecho en ese país y de sus principales diferencias con la situación en el

${ }^{2}$ Sólo quien excluya a priori la posibilidad de verdaderos cambios reduciría los modelos extranjeros de referencia a aquellos que se parecen bastante al que ya tenemos aquí. Pero si lo que tenemos no nos satisface, deberíamos atrevernos a mirar también cosas nuevas y diferentes, sin rendirnos de antemano ante la supuesta imposibilidad de traducirlas y aplicarlas a nuestro país (imposibilidad que muchas veces se asume de entrada cuando está aún por demostrar, paralizando nuestra capacidad de imaginar auténticas alternativas).

${ }^{3}$ La literatura especializada es inmensa, y el interés y los debates en torno a la enseñanza del Derecho están muy extendidos (quizá ello tenga bastante que ver con la tradición filosófica norteamericana del pragmatismo, que sigue impregnando toda la cultura de este país: como es sabido, la docencia, la filosofía y la psicología de la educación, fue uno de los temas favoritos de los pragmatistas, especialmente pero no sólo de Dewey). Como síntoma destacaré la publicación de la revista trimestral Journal of Legal Education, editada por la Association of American Law Schools. Esta prestigiosa revista es el principal medio de comunicación para el intercambio de ideas e información acerca del mundo de las facultades de Derecho, aunque no es la única revista dedicada a este tema. Como introducción e historia de la enseñanza del Derecho en Estados Unidos (con abundantísima información estadística) véase Stevens, Robert, Law School. Legal Education in America from the 1850's to the 1980's, University of North Carolina Press, Chapel Hill, 1983, pp. 334. Para un estudio mucho más breve y manejable, véase Cavers, David F., «Legal Education in the U.S.», en Berman, H. (ed.) Talks on American Law (revised edition), Vintage, Books, New York, 1971; o, más recientemente: Byse, Clark, «Fifty Years of Legal Education», 71 Iowa Law Review (1986), Sobre la enseñanza del Derecho en Harvard el texto ya clásico es Sutherland, A.E., The Law at Harvard, Belknap Press, Cambridge, MA, 1967. Entre las numerosísimas «guías» publicadas para orientar a futuros estudiantes de Derecho, debo destacar la única que se considera «oficial», publicada anualmente por el Law School Admission Council en cooperación con la ABA y la AALS (The Official Guide to U.S. Law Schools, Law Services Publications, Newton, PA), así como la editada por la «Society of Law School Teachers», con artículos de 20 profesores y prologada por el juez Brennan (Gillers, Stephen, ed., Looking at Law School, Meridian, New York, 3. ${ }^{a}$ edición, 1990, pp. $330)$. 
nuestro, con la única aspiración de ofrecer una descripción que pueda ser de alguna utilidad para el lector español. Aunque están estrechamente ligados, hablaré primero de los aspectos institucionales de la enseñanza del Derecho, y después de los contenidos y métodos didácticos de esa enseñanza. Vaya por delante que no pretendo ofrecer aquí una investigación sociológica «seria» con abundante información estadística: aunque ilustraré mi descripción con bastantes datos, lo que sigue es en buena parte una visión personal fruto de impresiones y experiencias en algunas facultades de Derecho americanas, de conversaciones con profesores y estudiantes, y de algunas lecturas.

\section{Aspectos institucionales: las facultades de Derecho y sus protagonistas}

\section{a) Las facultades de Derecho}

Lo primero que debo decir es que la enseñanza del Derecho en Estados Unidos no es en absoluto algo homogéneo, por lo que resulta difícil hablar de un único «modelo»o «sistema» americano de enseñanza del Derecho ${ }^{4}$. Además de las 175 facultades de Derecho «acreditadas» por la American Bar Association (la confederación de las «Bar Associations» o Colegios de Abogados de todos los Estados) existe todavía un buen número de facultades no acreditadas. Estas últimas son un vestigio del antiguo tipo de «Law schools» dependientes de instituciones educativas con ánimo de lucro no conectadas con la universidad, aunque hoy suelen organizarse como «corporations not for profit ${ }^{5}$. Su calidad es

${ }^{4}$ Una de las causas de las grandes desigualdades entre las diversas instituciones dedicadas a la enseñanza del Derecho en Estados Unidos es la ausencia de un control público de la enseñanza superior a nivel federal, al estilo del que ejercen en España instituciones como el Ministerio de Educación y Ciencia o el Consejo de Universidades. Cada Estado establece sus propios requisitos para la admisión al ejercicio profesional. Sólo entidades privadas (o semiprivadas) de ámbito nacional, como la American Bar Association (ABA) y la American Association of Law Schools (AALS), en cooperación con el Law School Admission Council, cumplen en la práctica una cierta función uniformadora, elaborando criterios generales en cuanto a acreditación de facultades, admisión de estudiantes, planes de estudios, titulaciones, habilitación para el ejercicio profesional, etc.

${ }^{5}$ Hay que tener en cuenta que, históricamente, y hasta hace no mucho, para ser admitido al «Bar examination» (la prueba que se exige en cada Estado para poder acceder al ejercicio profesional) no era necesario haber pasado por un período previo de educación formal en una facultad de Derecho. Los futuros abogados se formaban «a la inglesa», «leyendo Derecho» (en América, primero los Comentarios de Blackstone, y años después los de Kent) y trabajando como 
muy pobre y su prestigio casi está por los suelos: se trata más bien de «academias» privadas sin pretensiones intelectuales, concentradas en la preparación del «Bar exam» local, con clases nocturnas impartidas por abogados en ejercicio a estudiantes que trabajan y de los que más de la mitad abandonan antes de finalizar los cuatro o cinco años de que constan los estudios en este tipo de escuelas.

Entre las facultades de Derecho acreditadas, pertenecientes normalmente a una universidad (y a las que en adelante me referiré en exclusiva), las diferencias son también muy notables. Hay facultades públicas y privadas, de ámbito «nacional» y de ámbito «estatal» e incluso «local», grandes y pequeñas, de mayor o menor prestigio y calidad...

El número de facultades de Derecho privadas es algo superior al de las públicas. Estas últimas dependen siempre de los Estados, no del gobierno federal ${ }^{6}$, y aquéllas son instituciones en su mayoría laicas, sin ánimo de lucro, básicamente financiadas por fundaciones, grandes empresas o benefactores individuales (casi siempre antiguos alumnos), aunque también reciben ayudas públicas y beneficios fiscales ${ }^{7}$.

La distinción entre facultades de Derecho «estatales» $\mathrm{y}$ «nacionales» se basa fundamentalmente en la orientación de su curriculum, según se enfatice el Derecho del Estado donde radican (de donde reclutan y donde colocan a sus estudiantes) o bien se

pasantes o aprendices de un profesional en ejercicio (como las «Inns of Court» en Inglaterra). En 1966 todavía en 13 Estados cualquiera podía prepararse por su cuenta para dicho examen. Aunque hoy este método prácticamente ha desaparecido (actualmente casi todos los Estados exigen para la práctica profesional el título de Derecho expedido por una facultad acreditada por el ABA), todavía quedan muchos abogados en ejercicio que accedieron a la profesión de esa manera. Para unos breves apuntes históricos, véase infra, p. 69 y ss.

${ }^{6}$ En consecuencia, las universidades públicas (financiadas por los contribuyentes locales) admiten un mayor porcentaje de estudiantes residentes en su propio Estado, que deben pagar tasas de matrícula muy inferiores a las de los no residentes. Por el contrario, las universidades privadas no incluyen el factor geográfico entre sus criterios de admisión, y todos pagan la misma cantidad para matricularse.

${ }^{7}$ De las 175 facultades acreditadas por la ABA, 76 son públicas y 99 privadas. Entre estas últimas, 57 son «independientes», 32 son «religiosas», y 10 son «independientes con afiliación religiosa» (datos extraídos de la 13. ${ }^{a}$ edición del directorio American Universities and Colleges, editado por el American Council on Education). Proporcionalmente estas cifras, referidas a las facultades de Derecho, se alejan bastante, pero no extraordinariamente, respecto de la distribución de esas mismas categorías atribuidas a las universidades americanas en general: en números redondos hay en Estados Unidos unas 2.000 instituciones de enseñanza superior, de las cuales más del $70 \%$ son privadas, y entre éstas el número de universidades laicas es similar al de las religiosas. 
enseñe una especie de Derecho nacional, sin concentrarse especialmente en un Estado concreto, sino más bien haciendo hincapié en el Derecho y la práctica de los tribunales federales, y en una preparación metodológica general a partir de reglas y casos relevantes tomados de cualquier Estado, de manera que sus estudiantes puedan prepararse después para el «Bar examination» y la práctica en cualquier lugar del país (a pesar de sus importantes diferencias). Desde luego, esta distinción entre facultades «nacionales» y «estatales» o «locales» viene a coincidir en muchos casos con la distinción entre «privadas» y «públicas», respectivamente (las universidades públicas suelen orientar su enseñanza hacia el Derecho del Estado del que dependen). Pero esto no es siempre así: un buen número de facultades de Derecho públicas, como las de Virginia, Berkeley o Michigan (por citar algunas de las más prestigiosas), se consideran «nacionales» por los contenidos de su enseñanza, por la procedencia y destino final de sus estudiantes y por la influencia a nivel nacional de su docencia e investigación, a pesar de que institucionalmente dependen de sus respectivos Estados.

La diversidad afecta también al tamaño de las facultades de Derecho (medido por el número de alumnos), aunque esto no parece que sea un rasgo peculiar de Estados Unidos que sorprenda al lector español. Lo que quizá sí suscite la atención (y la envidia) de ese lector es la ratio estudiantes / profesores. Harvard Law School, la facultad más grande del país, tiene unos 1.800 alumnos -poco más de la mitad que la facultad de Derecho de Alicante- para un claustro de 63 profesores con exclusiva, a los que hay que añadir un buen número de «Profesores visitantes» (en 1991-92 hay 19) que también imparten docencia, así como «Lecturers on Law» (43 en ese mismo año), «Emeritus» (23), «teaching assistants» y «research assistants». Pese a estas cifras, uno de los defectos que se achacan con más frecuencia a Harvard es el de su masificación (sic). Y, efectivamente, Harvard es una facultad masificada si la comparamos con Yale, que tiene unos 600 estudiantes (con 57 profesores en exclusiva). Pero Yale suele considerarse todavía como un ejemplo de facultad «mediana $»^{8}$, con al menos el doble

${ }^{8}$ «Mediana» en cuanto al número de estudiantes, no de profesores: una facultad de tipo medio (es decir, con unos 600-700 alumnos), tiene unos 30 ó 35 profesores en exclusiva (sin contar a los profesionales -abogados, jueces, etc- contratados a tiempo parcial). De todas formas, hay que advertir que las envidiables ratios profesores / alumnos que parecen desprenderse de estas cifras pueden resultar ligeramente engañosas si no se tienen en cuenta factores como un cierto número -mayor que en España- de profesores «liberados» total o parcialmente de su carga docente para atender tareas administrativas (Decanos, Vicedecanos de todo tipo, etc.), o para dedicarse en exclusiva durante un año a 
de estudiantes que las «pequeñas» (según datos recientes, New Mexico tenía 338 alumnos, Wyoming 211, South Dakota 156...). Como cabe imaginar a la vista de estas cifras, incluso en las facultades grandes las clases tienen lugar en grupos de no más de 30 estudiantes, y en seminarios de 10 ó 15 (salvo en el primer curso, donde el curriculum está unificado y los estudiantes han de dividirse en «secciones» de más de 100 alumnos $)^{9}$.

Pero quizá el factor fundamental (al menos el que aquí más nos interesa) que distingue a unas facultades de otras no es el de su status institucional (público o privado), ni el ámbito geográfico, ni el tamaño, sino la «calidad»o «prestigio» de cada institución. En España un licenciado en Derecho es un licenciado en Derecho, y punto: no importa demasiado saber dónde estudió. En Estados Unidos las diferencias en cuanto a calidad de enseñanza, nivel del profesorado, bibliotecas y demás medios materiales, requisitos para la admisión de alumnos, dureza y diseño adecuado del plan de estudios, perspectivas profesionales de sus licenciados, etc., son abismales. En una palabra, existe un consenso generalizado en cuanto a la «reputación» de las distintas facultades de Derecho, que permite distinguir entre facultades «buenas» $\mathrm{y}$ «malas», «mejores» $\mathrm{o}$ «peores» ${ }^{10}$. La calidad de la enseñanza del Derecho en

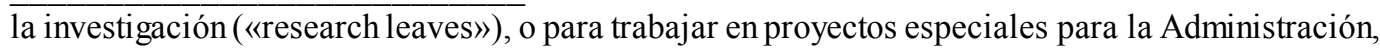
organizaciones sociales, instituciones internacionales, etc.

${ }^{9}$ He aquí las cifras globales: en las 175 facultades de Derecho acreditadas hay 132.433 estudiantes (la media es de 757 estudiantes por facultad) para unos 6.000 profesores en exclusiva (es decir, unos 35 profesores por facultad y 22 alumnos por profesor). A ello hay que añadir los estudiantes de las escuelas no acreditadas, cuyo número es difícil de calcular. Según Stevens (supra, nota 3, en p. 243) en 1979 habría unos 20.000.

${ }^{10}$ El lector español seguramente ya sabía que en América la «cotización» intelectual y profesional de un título académico depende mucho de la universidad que lo expida, pero quizá no se imagine hasta qué punto es verdaderamente el factor decisivo en una sociedad ferozmente competitiva. Incluso se publican diversos «rankings» ordenando numéricamente las distintas facultades, tras combinar múltiples factores como los que aquí he apuntado. Por supuesto, estas clasificaciones sólo pueden tener un mero valor indicativo, y siempre surgen discrepancias en cuanto al orden exacto establecido en las mismas. Pero cabe afirmar que, en líneas generales (tomando por ejemplo «grupos» de facultades cuya situación en el espectro resulta indiscutida al menos en su núcleo, aunque haya divergencias en la zona de penumbra), estos rankings reflejan el sentir generalizado de la comunidad jurídica. No hay, desde luego, una clasificación «oficial» publicada por las autoridades educativas ni por la ABA, que aconseja utilizar esas clasificaciones con mucha cautela. Pero es más que sintomático el hecho de que las distintas clasificaciones «privadas» no difieren sustancialmente entre sí (los factores «intangibles» se evalúan mediante amplias encuestas, sociológicamente fiables, dirigidas a académicos, jueces, abogados, etc.). Quizá la clasificación más divulgada es la que cada año publica el conocido semanario 
Estados Unidos ha mejorado mucho en las últimas décadas, y esto vale en general para todos los niveles de la amplia «escala de prestigio» a la que me estoy refiriendo. Los estándares para la admisión de facultades en la Association of American Law Schools cada vez son más estrictos; ha aumentado el prestigio social (y el salario) de los profesores, con una proporción creciente de dedicación exclusiva; las bibliotecas y demás medios materiales también han mejorado... Sin embargo, en términos relativos persisten las fuertes diferencias: en el extremo inferior de la escala sigue habiendo algunas facultades no muy distintas de las precarias escuelas «no acreditadas» antes aludidas, mientras que en el extremo opuesto brilla un grupo de facultades de Derecho de excelente calidad (cuyo número se ha incrementado). Una posible selección de las 15 primeras podría ser la siguiente: Yale, Harvard, Chicago, Stanford, Columbia, Michigan, New York University, Virgina, Duke, Pennsylvania, Georgetown, Berkeley, Cornell, Northwestern y Texas ${ }^{11}$.

En lo que resta de mi descripción de la enseñanza del Derecho

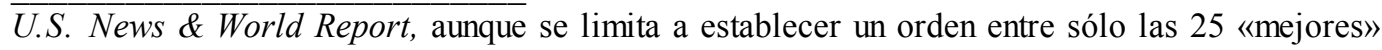
facultades de Derecho.

${ }^{11}$ He ordenado esta lista según el ranking establecido por U.S. News \& World Report. Como ya he apuntado, cualquier otra selección arrojaría resultados parecidos. Por ejemplo, Atiyah y Summers recogen una lista de 13 facultades (diplomáticamente colocadas por orden alfabético), en la que solamente está ausente una, Georgetown (que, de todas formas, ocupa el lugar $11^{\circ}$ en la clasificación que yo he recogido).

Probablemente, la principal discrepancia que suscita la clasificación de U.S. News se refiere a cuál merece ocupar el primer lugar. La rivalidad entre Harvard y Yale, al estilo de la de Oxford y Cambridge, no sólo viene de antiguo, sino que está hoy tan viva como siempre (emulando a sus mayores, ambas universidades compiten en todo, regatas de remo incluidas). No es por ello sorprendente -y sí algo divertido- escuchar a Robert Clark, Decano de la Facultad de Derecho de Harvard, arengando en tono irritado y completamente en serio a un distinguido público de nuevos licenciados y antiguos alumnos durante la muy solemne ceremonia de clausura del curso 1990-91, en la que tras arremeter contra la citada revista concluyó con un «¡Seguimos siendo el número uno!» que obtuvo los encendidos aplausos que hasta ese momento su discurso no había conseguido arrancar. Desde luego, la opinión más extendida sigue siendo hoy la de que Harvard, en Derecho, es efectivamente el número uno (véase, entre otros, Stevens, Sutherland, Atiyah y Summers, supra, notas 1 y 3). Incluso la propia clasificación de la denostada revista lo reconoce implícitamente: el relativamente novedoso primer lugar de Yale es el resultado final de agregar múltiples factores; en las clasificaciones parciales, según cada factor, Harvard está a la cabeza en tres de los más relevantes: «reputación entre los académicos», «reputación entre abogados y jueces» y «selectividad del alumnado». Pero sobre el liderazgo de Harvard en la enseñanza del Derecho en Estados Unidos volveré más adelante (infra, p. 73). 
en Estados Unidos, estaré pensando sobre todo en este tipo de facultades «importantes»o prestigiosas $^{12}$. Y ello no ya porque la gran heterogeneidad del conjunto total de instituciones dedicadas a la enseñanza del Derecho prácticamente me impediría hacer cualquier generalización (mientras que el reducido grupo de las principales facultades de Derecho es mucho más homogéneo), sino porque sencillamente las principales facultades son las que marcan la pauta a la hora de configurar la orientación y el impacto de la enseñanza del Derecho en general.

En este sentido, las facultades de Derecho punteras son en América instituciones verdaderamente poderosas, que ejercen una enorme influencia no sólo sobre las demás facultades, sino en general sobre el propio ordenamiento jurídico (según Atiyah y Summers, «incluso se podría decir que estas facultades dominan [sic] el sistema jurídico del país y su cultura jurídica»), e incluso sobre la vida política y económica de Estados Unidos. Sus estudiantes acaban ocupando lugares clave entre los mejores despachos de abogados, en la judicatura, en la Administración pública, en la actividad industrial y financiera, y en la política (el $40 \%$ de los Senadores y Representantes son juristas). Y en muchos casos esos «alumni» continúan manteniendo estrechas relaciones con su universidad durante el resto de su vida profesional. Pero la influencia de las grandes facultades de Derecho en todos estos ámbitos externos a la propia universidad se produce también de forma más directa, proyectándose tanto sobre la Jurisdicción como sobre la Administración y la Legislación.

En primer lugar, los profesores de Derecho gozan de un gran prestigio entre quienes se dedican al ejercicio de la profesión jurídica. Sus opiniones y escritos son tenidos en cuenta y citados con mucha frecuencia por abogados y jueces en todos los niveles. Atiyah y Summers ilustran esta influencia de los académicos sobre la orientación de los jueces recogiendo el ejemplo de un artículo publicado en 1976 en el que se defendía un incremento en la responsabilidad del fabricante por daños derivados de sus productos ${ }^{13}$. En pocos años este artículo fue citado en al menos 20 jurisdicciones estatales, aceptándose sus argumentos, y desde entonces el incremento en las indemnizaciones se ha extendido drásticamente y constituye hoy uno de los principales capítulos

${ }^{12} \mathrm{~A}$ la lista de las 15 facultades que aquí he nombrado cabría añadir un número aproximadamente igual de facultades que también reunirían las características básicas de lo que podemos llamar el modelo de «las principales facultades de Derecho» de Estados Unidos.

${ }^{13}$ Véase Owen, «Punitive Damages in Products Liability Litigation», 74 Michigan Law Review 1257 (1976). 
entre las causas de litigios ante los tribunales americanos. En realidad, según estos autores, prácticamente todo el Derecho actual de responsabilidad por productos («Products Liability Law») se ha originado en escritos académicos. El ejemplo utilizado por Atiyah y Summers no es desde luego un caso aislado. Bastaría repasar un puñado de sentencias tomadas al azar para descubrir con qué frecuencia los jueces americanos (y no sólo los tribunales de última instancia) citan y a menudo siguen las ideas propuestas en artículos escritos por profesores de Derecho. Y esto no es en absoluto un fenómeno reciente, sino algo bien arraigado en la cultura jurídica de este país ${ }^{14}$. La influencia de las facultades de Derecho sobre el mundo de la Administración de justicia se produce también directamente por el hecho de que muchos profesores son nombrados jueces ${ }^{15}$, o son contratados por eminentes despachos de abogados como asesores o incluso para defender casos ante los más altos tribunales, o son nombrados fiscales (caso del profesor Archibald Cox, protagonista del famoso asunto Watergate como «Special Prosecutor»), o dirigen seminarios y programas de «formación continuada» para jueces y otros profesionales, etc.

Pero la influencia de los profesores de Derecho no se reduce a los análisis dogmático-jurídicos tradicionales orientados a la aplicación del Derecho y dirigidos a jueces y abogados: quizá la característica más peculiar del jurista-académico norteamericano,

${ }^{14}$ El ejemplo histórico que primero me viene a la cabeza es el del «derecho a la intimidad», introducido por los tribunales al hacerse eco del artículo «The Right of Privacy» (4 Harvard Law Review 193, 1890), publicado por Samuel D. Warren y Louis D. Brandeis en 1890 (veintiséis años antes de que este último se convirtiera en juez del Tribunal Supremo). En Roberson v. Rochester Foiding Box Co., Court of Appeals of New York, 171 N.Y. 538 (1902), la discusión en torno a dicho artículo dividió al tribunal, aunque la mayoría falló en contra del reconocimiento de tal derecho (véase las «opiniones» de los jueces Ch. J. Parker, por la mayoría, y J. Gray, por los disidentes). En 1905 el derecho a la «privacy» se reconoció judicialmente por primera vez (Pavesich v. New England Life Insurance Co., 122 Ga. 190, 50 S.E. 68, 1905). La expansión de este derecho, que culmina con el célebre caso Roe v. Wade, 410 U.S. 113 (1973), en el que se reconoció el derecho al aborto amparado por esa «privacidad», ha estado siempre ligada a su elaboración doctrinal en las facultades de Derecho. Para una rápida visión de los primeros 50 años de esa evolución, véase Hart, Henry; Sacks, Albert, The Legal Process, materiales no publicados, 1958.

${ }^{15}$ Como seguramente el lector ya sabe, la carrera judicial en Estados Unidos es bien distinta a la de España: los jueces no son cuasi-funcionarios que acceden por oposición; en América todos los jueces federales son nominados por el Presidente y confirmados por el Senado, mientras que existen diversos mecanismos -elección popular, nominación por el Gobernador, etc.- para la provisión de cargos en los diversos juzgados y tribunales de los distintos Estados. 
y con ello pasamos ya al ámbito del Ejecutivo, es su papel de experto en "public policy». Muchas agencias de la Administración pública (tanto federales como estatales), y también grandes empresas y fundaciones públicas o privadas, colegios de abogados, grupos de interés, etc., están continuamente encargando y financiando numerosas investigaciones empíricas en las facultades de Derecho, a menudo con un gran despliegue de medios y llevadas a cabo por equipos interdisciplinares de juristas, economistas, científicos y tecnólogos, sociólogos, etc., o bien simplemente se trata de consultas, dictámenes o estudios encargados a profesores de Derecho individuales. Muchos de estos profesores son auténticos especialistas en «políticas sectoriales» relativas a problemas como el medio ambiente, atención médica, energía nuclear, arbitraje privado, defensa y relaciones internacionales, vivienda y urbanismo, mercados financieros, relaciones laborales, terrorismo, etc. La enseñanza y la investigación de cuestiones de «policy» como éstas se aborda desde una perspectiva mucho más amplia (incluyendo aspectos económicos, sociológicos, científicos, etc.) que la del análisis técnico-jurídico de las tradicionales ramas del Derecho. En suma, la distinción entre juristas y «policy-makers» está mucho más difuminada en Estados Unidos que en España, y los profesores de Derecho juegan un papel más que relevante como asesores en la formulación de políticas públicas, incluso en los más altos niveles de la Administración federal ${ }^{16}$. Es muy frecuente que estos profesores de Derecho sean incluso llamados para ejercer temporalmente importantes cargos en la Administración, fenómeno que es ya toda una tradición en Estados Unidos (quizá los casos históricamente más llamativos sean los «éxodos» de profesores de Yale y Columbia -entre ellos, conocidos nombres del movimiento realista- para trabajar en la Administración Roosevelt, o el de buena parte del claustro de Harvard Law School trabajando para la Administración Kennedy) ${ }^{17}$.

${ }^{16}$ Atiyah y Summers llegan a afirmar que «probablemente la calidad de los profesores de Derecho de las principales facultades de Derecho americanas es significativamente mejor que la calidad de los funcionarios públicos americanos, incluso en el nivel federal, y ciertamente en el nivel estatal. Por lo tanto -continúan estos autores-, pocos legisladores o administradores americanos partirían de la presunción básica de que las políticas diseñadas por sus funcionarios serán más sensatas que las formulaciones alternativas emanadas de profesores de Derecho solventes» (op. cit., nota 1 , en p. 400 ).

${ }^{17}$ En la actualidad, cargos como el de «Solicitor General» o el de director de la División «anti-trust» del Departamento de Justicia son normalmente asignados a profesores de Derecho (véase Atiyah y Summers, op. cit., supra nota 1, en p. 401). 
Por último (aunque no menos importante) hay que señalar que la influencia de las principales facultades de Derecho alcanza también al Legislativo. No sólo la Administración, sino también el Congreso, y los órganos legislativos de los Estados, acuden al asesoramiento de los más prestigiosos profesores de Derecho. Estos participan en la gestación de reformas legislativas (a menudo a través de instituciones como el American Law Institute) ${ }^{18}$, y en los últimos tiempos han influido notablemente en lo que casi se puede calificar como proceso codificador en Derecho privado, con la elaboración de leyes uniformes para todos los Estados en Derecho mercantil general (Uniform Commercial Code ${ }^{19}$ ) o en materia concursal (Federal Bankruptcy Code), por citar un par de ejemplos.

En resumen, las facultades de Derecho americanas son, utilizando las palabras de Atiyah y Summers, «una de las fuerzas institucionales que compiten por ejercer influencia sobre el orden jurídico en su conjunto. Estas fuerzas incluyen, en particular, la judicatura, la abogacía, las ramas legislativas y ejecutiva del Gobierno, y las principales facultades de Derecho ${ }^{20}$. Atiyah y Sum-

\footnotetext{
${ }^{18}$ Nacido en 1923 por iniciativa de la AALS, el American Law Institute es un «centro, de juristas para el mejoramiento del Derecho», con unos 1.800 miembros (fundamentalmente profesores de Derecho). Su objetivo principal es «la clarificación y simplificación del Derecho americano luchando contra su incerteza, su complejidad y su falta de uniformidad. Su labor más destacada ha sido y sigue siendo la elaboración de los «Restatements» (enciclopédicas sistematizaciones del «case law» y sus principios en diversos sectores del ordenamiento, aunque formalmente carecen de carácter oficial) y su participación, junto a la National Conference of Commissioners on Uniform State Laws (donde también hay una importante presencia de académicos), en la redacción de diversas «Leyes Uniformes» o códigos posteriormente adoptados por los legisladores de muchos Estados (p. ej.: Model Penal Code, Uniform Rules of Criminal Procedure, Uniform Rules of Evidence, Uniform Commercial Code, Uniform Partnership Act, Federal Securities Code, etc.). En un país donde, además del sistema federal, existen cincuenta órganos legislativos y otras tantas estructuras jurisdiccionales produciendo continuamente decenas de miles de precedentes y de leyes escritas, cuyo manejo mantiene bien ocupados a los abogados, se entiende que sean los juristas académicos quienes adquieren el protagonismo en la tarea de unificar y poner orden en esa masa de materiales jurídicos.
}

${ }^{19}$ Por el protagonismo de Llewellyn en su elaboración, este código -hoy vigente en todos los Estados excepto en Lousiana, que recientemente lo ha adoptado de forma parcial- ha recibido los sobrenombres de «Hewellyn's Code», «Lex Llewellyn» o «Karl's Kode», aunque en realidad en dicha elaboración participaron cientos de juristas, entre ellos muchísimos profesores de Derecho. (Véase Twining, William, Karl Llewellyn and the Realist Movement, University of Oklahoma Press, 1973, pp. 574, esp. caps. 11 y 12).

${ }^{20}$ Estos autores hablan además de «una especie de interacción positiva» entre las facultades de Derecho y estas otras instituciones, que produce algo así 
mers llegan a decir poco después que, en este sentido, «las principales facultades de Derecho son las más importantes» de entre dichas instituciones ${ }^{21}$, lo cual a mí me parece ya una exageración. No obstante, estos autores tienen razón al destacar un rasgo de las grandes facultades de Derecho que las sitúa en una posición de ventaja en esa «competencia» con otras instituciones: estas facultades, son «verdaderas instituciones nacionales en un país que (aparte del Gobierno federal y de la gran industria) tiene pocas instituciones verdaderamente nacionales». La diversidad y la dispersión geográfica de la judicatura, de la abogacía, o de los órganos ejecutivos y legislativos de los Estados, hacen difícil hablar de una cultura jurídica común a todo el país centrada en estas instituciones. Esa cultura jurídica común, si es que existe, irradia sobre todo de las principales facultades de Derecho, que son mucho más homogéneas.

Ya hemos visto en qué sentido las facultades de Derecho más prestigiosas de Estados Unidos son realmente «importantes». A continuación debo completar el perfil de este modelo de «las principales facultades de Derecho», haciendo hincapié en los rasgos de las mismas que más pueden llamar la atención al lector español. Para ello puedo comenzar aplicándoles las categorías clasificatorias que introduje al principio: se trata de instituciones universitarias (aprobadas por la ABA y por la AALS ${ }^{22}$ ) generalmente privadas (con numerosas y destacadas excepciones ${ }^{23}$, nacionales (en el sentido ya visto), y de tamaño grande o mediano (para los estándares americanos). Institucionalmente gozan de una gran autonomía incluso dentro de sus propias universidades: elaboran sus propios presupuestos; contratan a su propio personal de administración y servicios; deciden la creación y la provisión de plazas de profesorado (sujeta formalmente a la aprobación del Presidente o de la Junta Directiva de la universidad) y fijan sus salarios; establecen autónomamente el plan de estudios, los criterios de

como un «efecto multiplicador», incrementándose la influencia de las facultades de Derecho. La idea resulta obvia: cuando un tribunal o un órgano legislativo siguen las ideas de un profesor, crece el prestigio de éste, lo cual a su vez anima a otros jueces o legisladores a prestar atención a los escritos de dicho académico.

${ }^{21}$ Op. cit., supra nota 1, en p. 407.

${ }^{22}$ Hay que advertir que no todas las facultades «acreditadas» por la ABA han sido «admitidas» como miembros de la AALS: esta última tiene 156 miembros, lo que representa aproximadamente el $90 \%$ de las facultades acreditadas por la ABA (que son 175).

${ }^{23}$ Véase supra, p. 45. A los casos de prestigiosas facultades de Derecho públicas mencionadas en ese lugar podría añadir ahora otros ejemplos, como Texas (Austin), U.C.L.A., Iowa (Iowa City), Wisconsin (Madison), Minnesota (Twin Cities) o North Carolina (Chapel Hill). 
admisión de estudiantes, las tasas de matrícula, el calendario escolar, etc. Aparte de este grado de autonomía, mayor que en España, los dos rasgos institucionales de las facultades de Derecho americanas que a mí me parecen más relevantes son su organización interna sin divisiones departamentales y su carácter de «Escuela de Postgrado» («Graduate School»). El primer dato se refiere sobre todo a la organización del claustro de profesores (a su formación y especialización, a sus formas de investigar y a su curriculum docente), mientras que el segundo atañe más directamente a la composición del alumnado. Continuaré por tanto mi exposición distinguiendo entre ambos colectivos, profesores y estudiantes.

\section{b) Los profesores}

En cuanto a los profesores, a lo ya dicho hasta ahora debo añadir algunos datos que sirvan de información complementaria. En su gran mayoría su dedicación a la universidad es a tiempo completo: su trabajo de asesoramiento o de investigación destinada a entidades públicas o privadas al que antes me he referido suele realizarse en atención a encargos concretos, y no es tan frecuente que el profesor de Derecho tenga abierto un despacho profesional permanente al que dedica la mitad de su jornada de trabajo habitual. Esto no quiere decir que carezcan de experiencia en el ejercicio de la profesión: al igual que los jueces, los profesores de Derecho norteamericanos suelen ser reclutados entre profesionales en ejercicio, y en el momento de su nombramiento muchos cuentan ya con varios años de experiencia como abogados, ayudantes de jueces o fiscales, asesores de empresas privadas, organizaciones sociales o agencias de la Administración, etc. (a diferencia de lo que suele suceder en España, un joven licenciado en Derecho casi nunca tiene posibilidades de iniciar la carrera académica sin haber pasado antes por un período, aunque no sea muy largo, de experiencia profesional fuera de la universidad). El grado de doctor no es un requisito formal, y de hecho muchísimos profesores no han pasado por los cursos de doctorado y la tesis en una facultad de Derecho ${ }^{24}$. El nombramiento o contratación de nuevos

${ }^{24}$ Esto se explica por el carácter de estudios de postgrado que la carrera de Derecho posee por sí misma (véase infra, p. 62), de manera que el título que se expide a todos los estudiantes que concluyen los tres años de carrera (lo que para nosotros sería la licenciatura) es ya el de doctor en Derecho (J.D., Juris Doctor). Los estudios pueden continuar con un Master (LL.M., Master of Laws) de uno o dos años, que suele incluir un trabajo final similar a una tesina, e incluso con 
profesores, en todas las categorías, se decide por mayoría cualificada (normalmente, dos tercios) en el seno de un comité de catedráticos presidido por el Decano («Appointments Committee»). Formalmente, el Rector o Presidente de la universidad suele tener la última palabra, pero resulta absolutamente excepcional que interponga su veto a un nombramiento aprobado por dicho comité. Aunque se trate de universidades privadas, una vez que se confiere posesión o «tenure» a un profesor, su inamovilidad en la plaza se aproxima a la del profesor numerario que se convierte en funcionario en la universidad pública española. Por lo demás, los mecanismos y criterios para la contratación y ascenso de profesores en las facultades de Derecho públicas americanas no difieren sustancialmente de los de las privadas. Estos mecanismos se asemejan bastante a los propios de empresas privadas que compiten por los mejores «fichajes» en un libre mercado de cerebros. Por ejemplo, no se ofrece el mismo sueldo a todos los profesores. Las facultades de Derecho deciden autónomamente el establecimiento de una escala de salarios, con un «diferencial profesional» que permite a las «Graduate Schools» profesionales (como Derecho, Medicina o Empresariales) ofrecer salarios superiores a los del resto de Departamentos de su propia universidad. Dentro de esta escala, la facultad puede ofrecer mejores salarios a aquellos académicos más destacados que se desea atraer desde otras universidades (o desde otras profesiones jurídicas) o retener en la propia. Ello contribuye a acentuar las diferencias de calidad y prestigio entre las distintas facultades de Derecho, y a que en las mejores los sueldos de los profesores a veces sean incluso competitivos con los que podrían disfrutar en muchos otros puestos del sector público o privado (exceptuando, por supuesto, a los abogados de las grandes empresas y a los «partners» o socios-empresarios de las «megafirmas» de abogados $)^{25}$.

lo que en España llamaríamos doctorado (S.J.D., Scientia Juris Doctor), titulación que no todas las facultades ofrecen, y que en general sólo buscan -y, como digo, no siempre- quienes pretenden seguir la carrera académica. En América estos estudios, equivalentes a nuestro tercer ciclo, están diseñados de manera inversa a la de nuestro país: se da mucha más importancia que en España a los cursos de doctorado, en los que se ha de trabajar a fondo durante dos años, mientras que la tesis doctoral propiamente dicha suele ser bastante menos extensa que en España, y a ella no se dedican tantos años.

${ }^{25} \mathrm{El}$ sueldo de un profesor de mediana edad en una facultad prestigiosa supera fácilmente los 100.000 dólares anuales. En cuanto a las rentas que se pueden alcanzar en otras profesiones jurídicas en Estados Unidos, en lugar de aburrir al lector con más cifras y estadísticas le remitiré a los estudios que publica regularmente la revista Student Lawyer, editada por la ABA, donde se 
Pero el dato relativo al colectivo de profesores que más debo destacar -lo he anunciado ya- es el hecho de que las facultades de Derecho americanas no están estructuradas en Departamentos o Áreas de Conocimiento. No hay por lo tanto, al menos formalmente, profesores «de Derecho Penal», «de Derecho Administrativo», «de Derecho Mercantil», etc. Todos son «Professor of Law» (o «Associate Professor of Law», o «Assistant Professor of Law», de más a menos en la jerarquía del profesorado). Cada uno (con sus correspondientes ayudantes, «research assistants», «teaching assistants» y secretario administrativo) funciona como una «unidad» docente e investigadora independiente, que puede colaborar directamente en proyectos concretos con cualquier otro profesor de la facultad sin que medie (para bien o para mal) esa estructura intermedia que es el Departamento. Y es que en Estados Unidos no se conoce la división del Derecho (y de su enseñanza e investigación) por «ramas», con sus correspondientes Departamentos o Áreas, en el sentido tan acentuado que tradicionalmente ha compartimentado nuestra cultura jurídica. Esto no quiere decir, por supuesto, que el profesor de Derecho norteamericano domine por igual todo el ordenamiento jurídico sin necesidad de especializarse en algún sector del mismo. Pero la especialización es mucho más abierta y flexible. Ciertamente, existe un buen número de profesores a los que cabe encasillar como «penalistas», «constitucionalistas», etc. ${ }^{26}$ (sin que estas categorías tengan significado alguno a efectos administrativos), e incluso una cierta institucionalización de algunos gremios de especialistas en una rama del Derecho, al modo de nuestras «Asociación(es) Nacional(es) de Derecho $\mathrm{X} »{ }^{27}$. Pero normalmente un profesor de Derecho americano muestra simultáneamente no uno sino varios (a veces tres o cuatro) «centros de interés» en su actividad docente e investigadora, que además en muchos casos van cambiando a lo largo de su vida profesional. Estos centros de interés muchas veces no se corresponden sino que cruzan a través de las líneas divisorias entre las ramas del Derecho que nosotros conocemos, a menudo tienen un ámbito más reducido que el de esas amplias ramas o sectores, y en no pocos casos sus contenidos apenas guardan relación entre sí.

ofrecen datos comparados de los sueldos que reciben los licenciados en Derecho en sus diversas salidas profesionales.

${ }^{26}$ En Harvard, por ejemplo, Von Mehren es un especialista en Derecho Internacional y Derecho Comparado, Alan Dershowitz es un penalista, Morton Horwitz un historiador del Derecho, Laurence Tribe un constitucionalista...

${ }^{27}$ Por ejemplo, la «American Society of International Law», la «American Society for Legal History», la «American Society for Political and Legal Philosophy», o la «International Association of Penal Law-American Section»». 
Bruce Ackerman, por ejemplo, imparte cursos sobre «Jurisprudence» y sobre «Derecho Constitucional», pero también ha impartido recientemente cursos sobre «Derecho del medio ambiente» y sobre «Propiedad inmobiliaria»; Owen Fiss enseña «Derecho Procesal Civil», «Derecho Constitucional», «Propiedad inmobiliaria» y «Sociología del Derecho», y ha enseñado además «Equity», «Derechos Civiles» y «Burocracia». En suma, tanto respecto de la especialización del profesorado como del curriculum de cursos que constituye su docencia, conviene hablar más bien de «temas» o «instituciones jurídicas» que de «ramas del Derecho».

La inexistencia de Departamentos y la relativa difuminación de las fronteras entre ramas del Derecho tiene consecuencias importantes. Por un lado, tiene la ventaja de evitar la incomunicación entre gremios y Departamentos que se da en universidades como la española, donde se echa en falta una mayor colaboración interdisciplinar incluso en el seno mismo de las facultades de Derecho. Pero también es cierto que algunos Departamentos de las facultades españolas -en un número menor de lo que sería deseable- llegan a funcionar realmente como un equipo estrechamente compenetrado a la hora de organizar su docencia y de desarrollar líneas comunes de investigación, mientras que en Estados Unidos es difícil ver esos equipos relativamente numerosos trabajando eficientemente en un mismo campo del Derecho.

Pero lo que más me interesa aquí es señalar el alcance de la forma americana de organizar el estudio académico del Derecho a la hora de entender y valorar el carácter de la filosofía jurídica en aquel país. Es difícil hablar en Estados Unidos de un gremio de filósofos del Derecho «profesionales» como existe en España, dedicados en exclusiva a ese tipo de reflexión teórica acerca del fenómeno jurídico. Normalmente, quienes allí cultivan la filosofía o la teoría del Derecho siguen viéndose a sí mismos ante todo como «juristas» dedicados al Derecho positivo, que investigan y enseñan Derecho de Contratos, Derecho Constitucional, Derecho del Trabajo, etc., y que procuran además practicar la teoría jurídica pero no «por sí misma», sino directamente orientada al análisis de normas e instituciones concretas del Derecho americano. Es cierto que una parte significativa de la producción científica de estos académicos puede considerarse, utilizando nuestras categorías, como literatura filosófico-jurídica «propiamente dicha». Pero la parte cuantitativamente mayor, y quizá cualitativamente de superior calidad e interés, de esa producción consiste en trabajos que, al menos por razón de la materia, nosotros consideraríamos más bien «de juristas», a quienes los filósofos del Derecho españoles suelen referirse en tercera persona, como recalcando que su propia 
labor es de una naturaleza bien distinta: el filósofo del Derecho «reflexiona» acerca del trabajo del jurista, pero no lo «practica». La filosofía del Derecho norteamericana, en cambio, es sobre todo una filosofía del Derecho «aplicada» o, parafraseando una conocida distinción paralela, una «filosofía en el Derecho» (o «filosofía del Derecho de los juristas») más que una «filosofía del Derecho» (o «filosofía del Derecho de los filósofos», o mejor dicho, «de los filósofos del Derecho» $)^{28}$.

${ }^{28}$ Me refiero a la distinción entre «sociología del Derecho» (o «sociología del Derecho de los sociólogos») y «sociología en el Derecho» (o «sociología del Derecho de los juristas»), introducida por Henry C. Bredemeier («Law as an Integrative Mechanism», en EVAN, William M., ed., Law and Sociology, New York, 1962) y difundida entre nosotros por Renato Treves. Véase Treves, Renato, «Tre Concezioni e una proposta» $\mathrm{y}$ «Considerazioni conclusive», abriendo y cerrando el debate en torno al status científico y académico de la sociología jurídica en Italia publicado en Sociologia del Diritto, 1974, Nos. I y II. Parte de dicho debate, aunque referido a la sociología del Derecho, presenta en mi opinión un claro paralelismo con el punto que estoy tratando aquí. Sobre la defensa, frente a Treves, de la «sociología en el Derecho», véase el artículo de Giovanni Tarello en ese mismo debate (Tarello, Giovanni, «La sociologia nella giurisprudenza», Sociologia del Diritto, I, 1974, pp. 40-51).

Por otra parte, como también es sabido, la distinción entre «filosofía del Derecho de los filósofos» $y$ «filosofía del Derecho de los juristas» fue introducida por Bobbio en un artículo publicado precisamente en el mismo año que el de Bredemeier (Bobbio, Norberto, «Nature et fonction de la philosophie du droit», Archives de philosophie du droit, n. 7, 1962, pp. 1-11; cito por la traducción castellana recogida en Bobbio, Norberto, Contribución a la Teoría del Derecho, ed. a cargo de A. Ruiz Miguel, Fernando Torres Editor, Valencia, 1980, en pp.91-101). En ese lugar, Bobbio ya aludía a esta idea, aunque referida a «la tradición inglesa», cuando dice que «la diferencia entre filosofía del Derecho de los filósofos y filosofía del Derecho de los juristas es allí menos tajante». No obstante, la distinción que Bobbio está trazando en este trabajo es más bien una distinción digamos «previa», que no coincide exactamente con la que yo quiero señalar aquí. Bobbio está pensando sobre todo en el contraste entre, por un lado, lo que él llama una filosofía del Derecho como «filosofía aplicada», en el sentido de determinadas orientaciones de la «filosofía general» que el «filósofo» a secas, sin ser jurista, aplica como «inspiración y guía» para abordar dos problemas generales del Derecho y de la justicia»; y, por otro lado, una filosofía del Derecho practicada «por juristas que se elevan a la filosofía» y no por «filósofos que se rebajan hasta el mundo del Derecho» («juristas-filósofos» y no «filósofos-juristas»). En suma, lo que Bobbio reivindica es que los filósofos del Derecho sean juristas y no simplemente «filósofos puros» preocupados por el Derecho (y cita como ejemplos, entre los «juristas», a Thering, Santi Romano, Ehrlich, Kelsen, Ross o Hart, frente a «filósofos» como Adolf Lasson o Giovanni Gentile). En este sentido, me parece claro que la filosofía del Derecho practicada en España es casi exclusivamente una filosofía del Derecho «de los juristas»: dejando aparte nuestra convivencia con «los éticos» en una misma «Área de Conocimiento» (en lo que no voy a entrar ahora), los filósofos del Derecho españoles somos casi todos juristas y enseñamos en las facultades de Derecho 
Yo creo que lo anterior resulta esencial para poder valorar en su justa medida el trabajo de estos «filósofos del Derecho» americanos, sin exigirles más de lo que quieren y pretenden ser. Un tipo de crítica general bastante habitual contra la teoría jurídica norteamericana, esgrimida sobre todo por filósofos del Derecho europeos, consiste en señalar su escasa formación filosófica y / o filosófico-jurídica, la forma simplificada o insuficientemente sofisticada con que manejan conceptos o teorías que son moneda común en la teoría del Derecho contemporánea, el «no haber leído (o haberlo hecho de manera superficial) a...» o el «eso ya lo dijo $\mathrm{X}$ hace muchos años». Seguramente es cierto que muchos de ellos no conocen suficientemente a autores como Kelsen, Ross, Bobbio o incluso Hart, o no han analizado su obra con la misma profundidad con que se ha hecho en Europa. Pero también es cierto que ellos, desde una actitud más pragmática, consiguen acceder mejor a un auditorio de juristas más amplio (tanto dogmáticos del Derecho positivo en las universidades como abogados, jueces y demás protagonistas del funcionamiento del Derecho «en acción»), algo que al menos debería hacernos reflexionar sobre las limitaciones prácticas de nuestra situación de «superioridad intelectual» ${ }^{29}$.

(aunque es cierto que todavía algunos lo olvidan y se dedican a la filosofía sin apellidos, abandonando incluso la reflexión más general acerca del Derecho). Ocurre que, siendo juristas, cultivamos una filosofía del Derecho que, aunque no sea simplemente una filosofía general aplicada al Derecho, sigue estando demasiado alejada del trabajo práctico de los juristas del Derecho positivo que manejan códigos y sentencias. Bobbio enfatiza el contraste entre «filósofos», por un lado, $\mathrm{y}$ «juristas» que son «filósofos del Derecho», por otro. Yo me estoy refiriendo en cambio al contraste entre estos últimos y los dogmáticos o prácticos del Derecho. Cuando reivindico el término «aplicada», no me refiero a la filosofía general aplicada al fenómeno jurídico globalmente considerado, sino a la filosofía del Derecho aplicada al Derecho positivo.

${ }^{29}$ Yo creo que, efectivamente, uno de los principales problemas de la teoría del Derecho en países como el nuestro es precisamente esa escasa influencia que los filósofos del Derecho ejercemos sobre los juristas. Me temo que, en general, los dogmáticos del Derecho conocen muy poco del trabajo de los filósofos del Derecho, por no hablar de jueces y abogados. Y a ello contribuye sin duda, y en muy buena medida, la rigidez de la división de las facultades de Derecho en Arcas de Conocimiento (y del plan de estudios en «asignaturas»). Los americanos lo tienen más fácil, ya que esa rigidez no existe. Pero los obstáculos institucionales no deberían servirnos de excusa para dejar de intentar un cambio de actitud, orientando el discurso filosófico-jurídico en un sentido más próximo a los problemas que preocupan a los juristas. Hay que reconocer que practicar una «filosofía en el Derecho» verdaderamente «aplicada» a cuestiones concretas del Derecho positivo es una de las tareas más difíciles que puede plantearse un filósofo del Derecho, pero quizá sea de las más interesantes, también intelectualmente, y desde luego tendría un valor práctico mucho mayor. Yo no creo que esa 
A pesar de sus carencias filosóficas, creo que al menos se debe reconocer a muchos académicos americanos el mérito de tratarse de juristas prácticos interesados en introducir instrumentos tomados de la teoría del Derecho, la filosofía, la teoría social (y también la economía, la sociología, la crítica literaria), etc., en sus estudios jurídicos. Algo que no se puede decir que hagan con frecuencia nuestros civilistas, administrativistas, laboralistas, etc. Y aunque fuera cierto que el nivel filosófico-jurídico de aquéllos es más pobre que el de los filósofos del Derecho europeos, la comparación más justa habría que establecerla no con esos especialistas dedicados en exclusiva a la reflexión teórico-jurídica, sino con los dogmáticos de las distintas ramas del Derecho positivo. En esta otra comparación, el grado de formación teórica de los juristas norteamericanos seguramente sale mucho mejor parado. Reprochar a los americanos por no dominar a fondo la teoría del Derecho de Hart puede ser una acusación tan (im)pertinente como la de echar en cara a un filósofo del Derecho español su relativa ignorancia del Estatuto de los Trabajadores, de la dogmática jurídico-laboral y de la jurisprudencia de nuestro Tribunal Central de Trabajo. Trabajos como el de Karl Mare -por seguir con el ejemplo del Derecho laboral- sobre la National Labor Relations $\mathrm{Act}^{30}$ es un ejemplo más que digno de cómo es posible combatir el divorcio entre la teoría o la filosofía del Derecho y los análisis dogmático-

tarea obligue necesariamente a rebajar el nivel del discurso filosófico-jurídico, aunque en ocasiones ése sea un precio que quizá se deba estar dispuesto a pagar, hasta cierto punto, si se quiere acceder a (e influir en) un público de juristas apenas iniciado en las complejidades de dicho discurso. Y, en todo caso, nunca impediría continuar practicando, además, la filosofía del Derecho para filósofos del Derecho -que sin duda tiene valor por sí misma- al estilo en que se viene desarrollando hasta ahora. Alguien podría decir que la orientación aquí defendida ya viene siendo practicada por los filósofos del Derecho europeos, y ciertamente así es en el caso de algunas obras (por lo demás, más bien «periféricas») de los «grandes», como Kelsen o Hart. Pero yo creo que, al menos en nuestro país, ese enfoque sigue siendo la excepción más que la regla, y que la preocupación de los filósofos del Derecho por conocer y discutir a fondo la regulación positiva y la elaboración doctrinal de (al menos algunas) instituciones concretas del Derecho positivo, para arrojar algo de luz sobre ellas desde la filosofía del Derecho, no va en general más allá de publicar manifiestos pidiendo que se aborde esta tarea (sin que el propio autor predique con el ejemplo) o de pretender cubrir el expediente buscando casi al azar algunas normas o sentencias que ilustren a modo de ejemplo sus discursos teóricos.

${ }^{30}$ Klare, Karl, «Judicial Deradicalization of the Wagner Act and the Origins of Modern Legal Consciousness, 1937-1941», 62 Minnesota Law Review 265 (1978); véase también Klare, Karl, «Critical Theory and Labor Relations Law», en Kairys, David (ed.), The Politics of Law, 2nd ed., Pantheon Books, New York, 1990, pp. 61-89. 
jurídicos, y de que merece la pena tomarse en serio los esfuerzos de algunos americanos en esta dirección, aunque a veces no estén al corriente de la última interpretación publicada en Italia sobre el sentido de la norma básica en el Kelsen de 1960.

\section{c) Los estudiantes}

En cuanto al colectivo de los estudiantes, ya he señalado, en cifras globales, su reducido número en comparación con países como el nuestro, y la excelente ratio entre la cifra de estudiantes y la de profesores. Las formidables ventajas de la enseñanza en seminarios y grupos reducidos se consigue, al menos en parte, pagando el precio de una fortísima selectividad, tanto económica como académica.

Solamente la matrícula en cualquiera de las 25 principales facultades de Derecho americanas supone alrededor de un millón y medio de pesetas al año ${ }^{31}$. Si a ello se añaden gastos de alojamiento y manutención ${ }^{32}$, seguro médico ${ }^{33}$, libros, etc., estudiar Derecho en Estados Unidos representa una inversión total (sumando los tres años de carrera) de al menos 8 millones de pesetas ${ }^{34}$, y eso llevando una vida austera de estudiante y sin pensar mucho en los gastos acumulados durante los cuatro años previos de «College» ${ }^{35}$, cuyos costes anuales son parecidos y que probablemente no se han terminado de pagar y arrastran sus correspondientes intereses. La reacción inicial de un estudiante español ante

${ }^{31}$ Y no estoy hablando sólo de Harvard o Yale. En realidad, las diferencias en cuanto a los costes de matrícula entre las facultades de superélite y otras que no lo son tanto apenas es significativa. Sí lo es la diferencia entre las públicas y las privadas, aunque no siempre (Michigan, por ejemplo, cuesta más que Harvard) y quizá no tanto como uno podría imaginar (entre este grupo de 25 facultades, las públicas cuestan entre 8,000 y 10.000 dólares, cantidad sensiblemente inferior pero todavía respetable).

${ }^{32}$ La gran mayoría de estudiantes viven fuera del hogar familiar, a menudo a cientos o miles de kilómetros de distancia.

${ }^{33}$ Como probablemente sabe el lector, el sistema de sanidad en Estados Unidos -una de sus principales asignaturas pendientes, sobre la que existe hoy un vivo debate- está fundamentalmente en manos privadas, y pasar una temporada en un hospital sin estar cubierto por un costoso seguro privado puede significar literalmente la ruina para una familia de clase media (sólo la cama de hospital cuesta cerca de 100.000 pesetas por noche).

${ }^{34}$ Según el catálogo informativo de Harvard Law School para el curso 1991-92, el «presupuesto estándar» que debe estimar un estudiante soltero para los nueve meses del curso académico asciende a 28.135 dólares.

${ }^{35}$ Sobre el sistema de «College», previo al ingreso en la «Gradute School», véase infra, p. 62 y ss. 
estas cifras supongo que será la de pensar que en América hay que ser millonario para empezar a plantearse la posibilidad de estudiar Derecho. Desde luego, estos precios de la universidad americana representan por sí solos una barrera insalvable para grandes masas de la población, y contribuyen de manera importante a las escandalosas desigualdades sociales que padece este país ${ }^{36}$. Pero eso no quiere decir que no existan en Estados Unidos mecanismos a través de los cuales muchos estudiantes de clase media e incluso baja consiguen superar esta selectividad económica ${ }^{37}$. La universidad americana es sin duda mucho más elitista económicamente que la española, pero quizá no tanto como las cifras de los costes de matrícula pueden llevar a pensar. Además de un complejo sistema de becas públicas y sobre todo privadas (incluidas las de las propias universidades), muchas de las cuales están basadas en criterios fundamentalmente económicos (no siempre hay que ser un genio, además de carecer de recursos, para conseguirlas), o del hecho de que los estudiantes siempre encuentran trabajo a tiempo parcial o durante el verano, ofrecido por la propia universidad o por algún despacho de abogados, sin duda el mecanismo más utilizado es el de los créditos personales proporcionados por la misma universidad o por entidades privadas, a un precio a veces ligeramente inferior (sólo ligeramente, dos o tres puntos) al ordinario del mercado. Muchas familias abren un fondo en su banco para financiar los futuros estudios universitarios de sus hijos cuando éstos todavía están tomando el biberón, pero cualquier estudiante puede también conseguir fácilmente un crédito presentando en el banco la carta de admisión a una facultad de Derecho, al menos si esa facultad es una de las 20 ó 30 más cotizadas. Una carta de admisión firmada por el Decano de la facultad de Derecho de Stanford o de Columbia representa dinero en efectivo, por la sencilla razón de que el banco sabe que en sólo tres años el

${ }^{36}$ El típico contraargumento que suele esgrimirse en el debate acerca de la comparación entre el sistema americano y el modelo europeo de universidad pública (además de las ventajas de una universidad no masificada) es el de que en países como España todos los contribuyentes, incluidos los de rentas más bajas, están financiando la educación universitaria de un privilegiado sector de estudiantes mayoritariamente de clase media o media-alta que en muchísimos casos podrían sufragar el coste real de esa enseñanza (en España las tasas de matrícula sólo cubren aproximadamente el 20\% de esos costes reales). Pero este trabajo no es el lugar para entrar en ese debate.

${ }^{37}$ Téngase en cuenta además que los precios de matrícula aquí señalados corresponden al grupo de las universidades más importantes: una vez que salimos de este grupo (dentro del cual, como he dicho, no existen diferencias sustanciales), los costes se van reduciendo a medida que descendemos en el ranking de universidades. 
«tenedor» de ese «título-valor» estará ya ganando más de ocho millones de pesetas como sueldo inicial en una de las principales «Law firms» del país (con la perspectiva además de captar para el futuro a uno de sus mejores posibles clientes individuales). Y es que en Estados Unidos estudiar Derecho en una buena facultad se enfoca muchas veces como una inversión económica, costosa pero segura. La selectividad económica de las principales facultades se convierte así en un arma de doble filo para quien consigue acceder a ellas: por un lado, supone un sacrificio económico enorme, una hipoteca que no se termina de amortizar hasta bien entrada la vida profesional (a veces, más de 10 años); pero por otro lado, en la medida en que contribuye a reducir el número de estudiantes, contribuye también a aumentar su cotización en el mercado de trabajo una vez finalizados los estudios ${ }^{38}$. El sueldo inicial de unos ocho millones como «asociado» en un buen despacho colectivo se convierte en más de diez millones al cabo de cinco años, y si el joven abogado asalariado llega a convertirse en socio-empresario («partner») de esa «Law firm», sus ingresos pueden superar los treinta millones de pesetas anuales ${ }^{39}$.

La selectividad económica, siendo un factor importantísimo, no llega a ser tan decisivo como la selectividad académica: al fin y al cabo, de poco sirven los recursos económicos si no se satisfacen los durísimos criterios académicos exigidos para la admisión en una buena facultad de Derecho, y a la inversa, quien satisface esos criterios puede encontrar con relativa facilidad la forma de financiar sus estudios.

Para empezar, todos los estudiantes de Derecho deben haber cursado previamente una carrera universitaria de cuatro años. En Estados Unidos, las facultades de Derecho son escuelas de postgrado («Graduate Schools»), al igual que un reducido número de otras «escuelas profesionales», básicamente Medicina, Empresariales («Business School») y algunas otras escuelas técnicas. El sistema es el siguiente: tras concluir el bachillerato («High School») a los 17 ó 18 años, el estudiante americano debe conseguir la

${ }^{38}$ Gerald Lee Wilson expresa así el dilema económico al que se enfrenta el futuro estudiante de Derecho: «Dado que estudiar Derecho es caro, la pregunta " ¿puedo realmente permitirme ir a la facultad X?" resulta fundamental. Pero dado que estudiar Derecho es una inversión, la pregunta “¿puedo permitirme no ir a la facultad X?” también debe ser considerada (Wilson, Gerald Lee, «Selecting a Law School», en Gillers, Stephen, ed., op. cit., nota 3, en p. 24).

${ }^{39}$ Estos datos están extraídos de The Official Guide to U.S. Law Schools, op. cit., nota 3. Hay que tener en cuenta además que en Estados Unidos los impuestos son más bajos que en España, y el coste de la vida es similar o incluso inferior al de España. 
admisión en el «College» de una universidad (la admisión se determina fundamentalmente en base al expediente académico y a un examen especial de selectividad ${ }^{40}$ ), donde tras cuatro años obtendrá el título de «Bachelor», aproximadamente equivalente a nuestra licenciatura universitaria. Subrayo «aproximadamente» porque el sistema es bastante distinto al de España. Por un lado, en el College no se elige exactamente una «carrera» como un todo, con un plan de estudios propio y que se cursa en una facultad independiente de las demás. El College es un único centro, dividido en Departamentos, que ofrece un amplísimo abanico de cursos de ciencias, humanidades, disciplinas sociales, técnicas, etc., entre los cuales cada estudiante escoge los que le interesen para construir su propio curriculum, y todos obtienen la misma titulación (en ciencias sociales y humanidades, B.A., «Bachelor of Arts», y en ciencias, B.S., «Bachelor of Sciences»). Esto no quiere decir tampoco que los estudios constituyan un «potpourrí» caótico de cursos a gusto del consumidor. El curriculum se suele estructurar según su orientación o perfil, de forma más flexible que nuestras carreras; cada estudiante puede elegir un «major» y un «minor», es decir, unos cursos básicos sobre un campo amplio del saber y otros cursos más especializados en una determinada dirección. Por otro lado, la cotización académica, social y económica de los estudios de College es quizá algo menor que la de nuestras carreras universitarias. Solamente con una titulación a nivel de College no resulta fácil encontrar un trabajo especializado con una buena remuneración, y son cada vez más los estudiantes «graduados» que deben continuar sus estudios en busca de un Master o un doctorado (o ir a una «Graduate School» profesional) que incremente sus perspectivas profesionales (mientras que en España los estudios de tercer ciclo casi siempre interesan sólo a quienes desean iniciar la carrera docente en la universidad). Esto es así en parte debido a que los estudios de College no son de un gran nivel, al menos comparados con los estudios universitarios en Europa. Hay que tener en cuenta que la calidad de las enseñanzas medias en Estados Unidos deja mucho que desear, y el College debe suplir muchas carencias originadas en la High School, aunque quizá sea exagerado considerar al College simplemente como un «segundo bachillerato».

Una vez graduado en el College, el aspirante a estudiar Derecho

${ }^{40}$ El ACT (American College Test), que consta de cuatro secciones: matemáticas, ciencias, inglés y ciencias sociales. Muchas universidades exigen en cambio (o además) el SAT (Scholastic Aptitude Test), de estructura similar pero de un nivel algo superior. 
debe someterse a un examen de selectividad específico para estos estudios, organizado a escala nacional por el «Law School Admission Council»" ${ }^{41}$ Se trata del «Law School Admission Test» (LSAT), definido oficialmente como «un test estandarizado (...) diseñado para medir las habilidades esenciales para el éxito en la facultad de Derecho». Dado que, al igual que en España, en la formación previa a la carrera de Derecho no hay cursos específicamente jurídicos, en el LSAT no se exige tanto conocimientos de Derecho cuanto aptitudes básicas para su estudio en el futuro: capacidad de lectura y comprensión de textos complejos, saber redactar de manera coherente y ordenada, habilidad para manejar y procesar información y extraer conclusiones de ella, capacidad de síntesis y de análisis, y en general la aptitud para el razonamiento lógico y la argumentación crítica. Aunque no sea de conocimientos, el LSAT no es un examen fácil, y los estudiantes suelen prepararlo concienzudamente durante meses. En realidad, el LSAT no es un examen que se aprueba o se suspende: simplemente otorga a cada estudiante una determinada puntuación, que será suficiente o no para la admisión según los criterios particulares de cada facultad ${ }^{42}$. Esta puntuación generalmente se promedia con el UGPA («Undergraduate Grade Point Average»), es decir, el promedio de las notas obtenidas en los cuatro años de College. El UGPA es valorado por las facultades teniendo en cuenta la dificultad de los cursos escogidos (utilizando estadísticas de las notas medias obtenidas por varias promociones) y la idoneidad de los mismos como base para los estudios de Derecho. Pero hay que advertir que esto último suele entenderse de una manera muy flexible: no se excluye a priori ningún curriculum $^{43}$, y en general no importa mucho cuál

${ }^{41} \mathrm{El}$ «Law School Admission Council» es una asociación de facultades de Derechos de Estados Unidos y Canadá que suele trabajar en cooperación con la ABA y la AALS, encargándose sobre todo de colaborar con las facultades de Derecho -y con los estudiantes que aspiran a ingresar en ellas- en todo el proceso de admisión. Sus programas son administrados por el «Law School Admission Services».

${ }^{42}$ Los resultados se traducen a una escala de 10 a 48 puntos. En convocatorias recientes, dos tercios de los examinandos obtuvieron entre 22 y 38 puntos. Pero las puntuaciones medias de los admitidos en las 25 mejores facultades se situaron entre 40 y 45 puntos.

${ }^{43}$ Para muchas facultades la diversidad de sus estudiantes es un factor de enriquecimiento mutuo en el seno de ese mismo colectivo, y constituye por sí misma un valor digno de protección. Aparte de las políticas de «acción afirmativa» en relación con las minorías raciales o étnicas, las facultades de Derecho suelen admitir un cierto número de estudiantes llamados «no convencionales» en atención a su formación previa (quienes en el College estudiaron materias muy alejadas del Derecho, como por ejemplo música o ciencias puras), e incluso a sus 
haya sido el «major» del candidato si eligió cursos que estimulan el dominio del lenguaje oral y escrito y la capacidad de razonamiento crítico. Por supuesto, siempre es preferible haber estudiado materias como historia, ciencia política, sociología, filosofía, economía, lengua y literatura o -cada vez más- contabilidad.

El promedio del LSAT y del UGPA constituye el «factor numérico», que es con mucho el principal, pero no el único (salvo en algunas universidades públicas), en el proceso de admisión. Éste termina de perfilarse atendiendo a factores como entrevistas personales ante el comité de admisiones, cartas de presentación, experiencia de trabajo, actividades extracurriculares realizadas por el candidato, o los llamados «ensayos» que han de incluirse en cada solicitud respondiendo a preguntas tales como «¿por qué quieres estudiar Derecho?» o «háblanos de ti mismo», y con los que se busca conocer mejor tanto la habilidad del aspirante a la hora de redactar como los rasgos más sobresalientes de su personalidad y de sus intereses.

En resumen, la admisión en una buena facultad de Derecho acaba siendo para el estudiante un proceso muy complejo ${ }^{44}$, de enorme dureza y altamente competitivo. En cifras globales, algo menos de la mitad de quienes solicitan la admisión en una facultad de Derecho acreditada efectivamente la logran (este año ha habido 95.000 solicitantes para 44.000 plazas), pero si nos fijamos en las 25 mejores facultades los porcentajes de admitidos oscilan entre el 30,1\% (Iowa) y el 5,6\% (Yale) $)^{45}$.

Una de las consecuencias obvias de esta fuerte selectividad académica es la de un mejor nivel del alumnado en las facultades

características personales (extranjeros, de edad más avanzada, casados y con hijos, etc.). La experiencia de trabajo después del College, y la edad superior a la del estudiante típico, son factores cada vez más tenidos en cuenta en los procesos de admisión.

${ }^{44}$ Prueba de ello es la aparición de la figura del «prelaw adviser», un profesional de las universidades (en el nivel del College) encargado de asesorar a aquellos estudiantes que estén pensando en estudiar Derecho. Proliferan los cursos y las publicaciones de orientación a las facultades de Derecho y a sus requisitos y procedimientos de admisión, así como para la preparación del LSAT. El proceso de recopilación de información y de preparación de las solicitudes (cada estudiante suele presentar su candidatura en muchas facultades, a veces más de una docena) suele comenzar con meses e incluso años de antelación.

${ }^{45}$ Harvard ha admitido al 9,5\% de quienes lo solicitaron; Chicago al 14,2\%, Stanford al 8,0\% y Columbia al $16,1 \%$. Hay que tener en cuenta además que prácticamente todos los que son rechazados por estas facultades ostentaban presumiblemente unas excelentes credenciales, ya que de lo contrario ni siquiera habrían desperdiciado su tiempo y esfuerzos presentando su solicitud a una de estas instituciones. 
de Derecho americanas. Aunque se vea al College, en el peor de los casos, como un segundo bachillerato, éste es ya de nivel universitario, y el grado de formación y de madurez de un estudiante que se gradúa a los 22 años tras cuatro años de College es bastante superior al de nuestros estudiantes recién salidos del COU a los 18. Si a ello añadimos la abismal diferencia -y no sólo en cuanto a grado de dificultad, sino también en su adecuación para seleccionar específicamente candidatos a juristas- entre todo el proceso de selección antes descrito y nuestras pruebas de selectividad, que sirven para cualquier cosa menos para seleccionar, el resultado es un colectivo de estudiantes de Derecho americanos de excelente calidad, acostumbrados ya al éxito en los estudios.

Este carácter literalmente «selecto» de los estudiantes explica muchas cosas. Explica, por ejemplo, que la calificación de «suspenso» en una asignatura sea algo realmente excepcional, y que la figura del «repetidor» prácticamente no se conozca. Conseguir acceder a una buena facultad de Derecho resulta dificilísimo, pero una vez dentro la práctica totalidad de los «elegidos» acabarán sus estudios, y en no más años de los tres de que consta esta carrera ${ }^{46}$. Esto no significa que, una vez salvados los obstáculos de la admisión, el estudiante pueda dormirse en los laureles. Durante esos tres años (sobre todo en el primero) se exige un trabajo intensísimo, y los estudiantes, por muy brillantes que sean, deben llevar una vida parecida a la del licenciado español que prepara oposiciones de un nivel alto. Si, salvo rarísimas excepciones (debidas casi siempre a causas de índole extraacadémica), todos cumplen con el nivel mínimo exigido, no es porque éste sea bajo, sino porque se trata de estudiantes con una buena formación previa, intelectualmente aventajados, y que además trabajan duramente. Llama la atención ver, por ejemplo, lo concurridas que están las bibliotecas un domingo cualquiera del año -y no sólo en época de exámenes- hasta el último minuto en que permanecen abiertas, es decir, a las 12 de la noche. $\mathrm{Y}$ es importante recordar -todo hay que decirlo- el estímulo añadido que para ellos representa el coste económico que supondría repetir algún año. Por si fuera poco, las facultades ya se encargan por sí mismas de establecer un «régimen de permanencia» durísimo. Por ejemplo, mientras en España basta con aprobar una asignatura en el primer año para poder continuar, en Estados Unidos normalmente la cifra se invierte: hay que aprobar todas menos una de las seis

${ }^{46}$ El fracaso académico apenas existe. En cifras globales, menos del 5\% abandonan los estudios antes del final, cifra que desciende por debajo del $1 \%$ en las principales facultades. 
asignaturas de que suele constar el primer curso; nuestras seis convocatorias en América generalmente se reducen a dos, y el segundo intento debe realizarse necesariamente durante el año siguiente, ya que el «no presentado» equivale al suspenso ${ }^{47}$.

Una vez obtenido el título de Derecho (J.D.), los recién licenciados todavía deben superar el «Bar exam» exigido por el Estado donde deseen ejercer. En este examen se evalúan los conocimientos jurídicos generales así como las principales peculiaridades del Derecho del Estado en cuestión, la capacidad de «razonamiento jurídico» y la familiaridad con el código deontológico y con el régimen de responsabilidad profesional del abogado. Aprobar este examen no suele representar una gran dificultad para los licenciados del tipo de facultad de que venimos hablando ${ }^{48}$, aunque se ven obligados a prepararlo intensamente durante el verano inmediatamente posterior a su graduación. Un abogado sólo puede ejercer en aquel Estado en el que ha sido admitido mediante este examen ${ }^{49}$, aunque muchos Estados admiten también a aquellos abogados acreditados en otro Estado que hayan practicado la profesión durante un cierto número de años, o les conceden admisiones temporales para casos particulares. Desde hace algún tiempo existe además la posibilidad de someterse al «Multistate Bar Exam», un examen unificado reconocido por la mayoría de los Estados, que permite el acceso a la profesión en cualquiera de ellos (en este examen cada Estado añade un segundo ejercicio en el que se exigen conocimientos específicos del Derecho de ese Estado). Por otra parte, para ejercer ante los tribunales federales hay que satisfacer los requisitos establecidos por éstos, que varían según el tipo de tribunal. En los tribunales federales de distrito el requisito básico es simplemente haber sido admitido al ejercicio en el Estado en que ese tribunal federal esté localizado, mientras que en los tribunales federales de apelación suele exigirse el estar acreditando ante el más alto tribunal de algún Estado.

${ }^{47}$ De todas formas, hay que advertir que los regímenes de permanencia varían bastante de una facultad a otra y no es fácil generalizar. De nuevo, esta dureza se va relajando a medida que descendemos en la escala de «categoría» de cada facultad. Y en realidad no cabe hablar exactamente de un sistema de «convocatorias» limitadas, como en España, ya que allí se fija un complejo mecanismo de «créditos» que han de obtenerse para la obtención del título.

${ }^{48}$ No se piense por ello que el «Bar exam» es un coladero. No hace mucho en California, por ejemplo, lo suspendió el $52,5 \%$ de los que se presentaron, aunque también hay que decir que se trata de uno de los Estados donde las pequeñas «escuelas nocturnas» de Derecho son más numerosas.

${ }^{49}$ Por eso algunos abogados se someten varias veces al Bar exam, cada una en un Estado diferente, y las principales «Law firms» suelen abrir oficinas en muchos Estados. 
La contrapartida de toda esta selectividad económica y académica que he ido describiendo es la de unas muy buenas perspectivas profesionales para quien se gradúa en una facultad de Derecho, al menos si ésta se encuentra en el tercio superior del ranking. Describir la estructura y el carácter de la profesión jurídica en Estados Unidos excede con mucho los límites de este estudio, que quiere centrarse exclusivamente en la enseñanza del Derecho y no en todo lo que puede ocurrir después de la carrera. Me limitaré por ello a señalar que en general todos los licenciados en una buena facultad encuentran rápidamente trabajo como juristas. El problema del joven licenciado es más bien el de elegir entre las muchas posibilidades profesionales que se le abren. Posibilidades que, en el caso de una facultad prestigiosa, ni siquiera deben ellos salir a buscar, ya que incluso desde el primer año de carrera les llueven las ofertas sin moverse de la facultad. Empresas privadas, agencias del gobierno, organizaciones sociales y, sobre todo, grandes despachos colectivos («Law firms») acuden masivamente a las principales facultades de Derecho para entrevistar $\mathrm{y}$, en su caso, reclutar a futuros licenciados, ofreciendo trabajo durante el verano (a modo de período de prueba, con la vista puesta en un «fichaje» definitivo) a los estudiantes de primer y segundo curso, o proponiendo a los de tercero la incorporación inmediata para comenzar tan pronto como aprueben el Bar Exam. La oficina de empleo de la propia facultad («Placement Office» o «Office of Career Services») se encarga de canalizar y organizar todas estas ofertas, además de asesorar en general a sus estudiantes acerca de las salidas profesionales. En Harvard, por ejemplo, se ha institucionalizado una especie de «temporada de entrevistas» durante los meses de octubre y noviembre, feria a la que acuden representantes de más de 800 «Law firms» y empresas privadas para comprar (a veces en sentido no tan figurado) jóvenes promesas. Cada estudiante se apunta a tantas entrevistas como desee (la media es de unas 20). Ciertamente, el fantasma del paro no es algo que preocupe a estos estudiantes, lo cual no evita que entre ellos exista una feroz competencia por acceder a los mejores trabajos. El grado de prestigio de cada facultad de Derecho y, dentro de la misma facultad, el lugar que ocupe cada estudiante en el ranking de su promoción, son factores decisivos para determinar quienes consiguen los empleos más codiciados. También las entidades que acuden a contactar con futuros abogados compiten duramente entre sí por fichar a los estudiantes más brillantes, y en esta competencia casi siempre salen victoriosas las grandes «Law firms» (algunas de hasta 200 abogados), que ofrecen salarios formidables, así como una gran seguridad en el empleo, enormes posibilidades 
de formación y de promoción profesional, y un elevadísimo prestigio social ${ }^{50}$.

\section{Aspectos sustantivos: métodos y contenidos de la enseñanza del Derecho en Estados Unidos}

Hasta aquí mi exposición se ha centrado básicamente en lo que he denominado, en sentido muy amplio, aspectos «institucionales» de la enseñanza del Derecho en Norteamérica, es decir, cuáles son las características principales de las facultades de Derecho, cómo funcionan internamente en cuanto instituciones, qué papel juegan en su contexto social general y en relación con otras instituciones jurídicas, cuál es el perfil de los colectivos de profesores y estudiantes, etc.

A continuación me detendré en los aspectos que podríamos llamar «sustantivos» de esa misma enseñanza: se tratará de ver ahora qué es lo que ocurre «puertas adentro» en las aulas, es decir, qué se enseña y cómo se enseña, cuáles son los métodos (técnicas pedagógicas, materiales bibliográficos, sistemas de evaluación) y contenidos (orientación de la enseñanza, plan de estudios, etc.) de la docencia. Para ello comenzaré haciendo un poco de historia.

\section{a) El "case method" y sus origenes}

A principios del siglo XIX no existían los estudios de Derecho tal como los conocemos hoy. Como ya he apuntado, los abogados se formaban trabajando como pasantes, y aprobar el «Bar exam» -en aquellos Estados que lo exigían- era poco más que una formalidad $^{51}$. En este contexto surgieron las primeras escuelas de

${ }^{50}$ En cifras globales (referidas a todos los licenciados en Derecho americanos, que hoy son más de 800.000 ), el $74 \%$ se dedican al ejercicio privado de la profesión, de los cuales poco más de la mitad trabajan solos y el resto en una «Law firm»; el 13\% trabaja para la administración pública (incluyendo unos 10.000 jueces); el 12\% son ejecutivos a sueldo de empresas y asociaciones privadas; y cerca del $1 \%$ se dedica a la enseñanza. Pero si nos centramos en las facultades más importantes, aproximadamente el $70 \%$ de sus licenciados pasan a ingresar en una «Law firm», y el resto trabajan para bancos y grandes empresas del sector privado, para la administración o, en un porcentaje considerable (al menos el 10\%) como pasantes de jueces («judicial clerkships»), que en la mayoría de los casos después de unos años acaban trabajando en una «Law firm».

${ }^{51}$ Para entender el carácter particularmente abierto del acceso a la abogacía en estos años hay que tener en cuenta que la primera mitad del siglo XIX fue la época de la llamada «democracia jacksoniana» (Andrew Jackson fue presidente 
Derecho, de carácter no universitario, cortadas según lo que podríamos denominar el «modelo Litchfield» ${ }^{52}$. En América siempre había habido abogados que se tomaban especialmente en serio la tarea de enseñar a sus pasantes. Algunos dedicaban cada vez más tiempo a esa labor y menos a sus clientes, admitían a un número cada vez mayor de pasantes e incluso comenzaban a cobrarles por ese aprendizaje, hasta que finalmente abandonaban el ejercicio de la profesión y su bufete se convertía en una escuela de abogados. Así surgió la célebre escuela de Litchfield (Connecticut), fundada en 1784 por el juez Tapping Reeve, y que puede considerarse la primera «facultad» de Derecho de Estados Unidos; funcionó hasta 1833. La enseñanza en este tipo de escuelas, con escasos medios, sin requisitos de admisión ni exámenes finales, duraba poco más de un año, y estaba exclusivamente orientada a la práctica. Pero el método docente incluía a menudo el de las conferencias, de las que los alumnos tomaban apuntes.

El «modelo Litchfield» terminó siendo absorbido por la enseñanza del Derecho de carácter universitario, inaugurada con la creación en 1817 de la primera facultad (ya sin comillas) de Derecho en la Universidad de Harvard. Aquí el modelo era Blackstone. Las conferencias que Blackstone impartió en Oxford a mediados del siglo XVIII, y que fueron la base de sus famosos Commentaries, en realidad no habían sido pensadas para la formación de juristas en la universidad, sino para un público más amplio, pero las facultades de Derecho siguieron su ejemplo y los Commentaries pronto se convirtieron en la «Biblia» de la enseñanza del Derecho tanto en Inglaterra como en Estados Unidos.

He afirmado que el modelo de Litchfield fue «absorbido» -más que «sustituido»por el modelo de Blackstone. Con ello quiero decir que, durante buena parte del siglo XIX, la enseñanza «universitaria» del Derecho, aunque con pretensiones intelectuales algo más ambiciosas que la de Litchfield, seguía arrastrando muchos de los rasgos del modelo anterior. Su nivel era bastante

entre 1828 y 1836). El populismo igualitarista y anti-elitista de esta doctrina política exaltaba las virtudes del «hombre medio» americano, e implicaba que todo buen ciudadano tenía algo así como un derecho innato al ejercicio de la profesión jurídica. La Constitución del Estado de Indiana es un buen ejemplo de este espíritu jacksoniano; en ella se establecía que «toda persona de buen carácter moral, siendo votante, tendrá derecho a ser admitido a la práctica del Derecho en todos los tribunales de justicia». Véase Benson, Lee, The Concept of Jacksonian Democracy, Princeton, 1961.

${ }^{52}$ Véase Friedman, Lawrence M., Introducción al Derecho Norteamericano, trad. cast. de Joan Vergé i Grau, Librería Bosch, 1988, pp. 402. He acudido a este texto para relatar la etapa inicial de este breve recorrido histórico. 
pobre, no había exámenes de ingreso ni de fin de curso (bastaba con pasar por ahí dos años y pagar la matrícula) y, sobre todo, la enseñanza seguía estrechamente orientada a la práctica profesional: estaba concebida más como un aprendizaje técnico en una escuela de capacitación profesional que como una disciplina académica «respetable» que se enseña en la universidad.

En realidad, la enseñanza universitaria del Derecho, tal como se entiende hoy, comienza a configurarse a partir de 1870. En ese año un abogado de Nueva York llamado Christopher Columbus Langdell (1826-1896) fue nombrado primero profesor y meses después Decano de la facultad de Derecho de Harvard (antes, la figura del Decano no existía). Langdell llevó a cabo una auténtica revolución en la enseñanza del Derecho.

Como Decano de Harvard, la obsesión de Langdell era precisamente reivindicar esa respetabilidad académica de la que carecía hasta entonces el estudio del Derecho en su país. Langdell sostiene una y otra vez que el Derecho es una «ciencia», aunque nunca sabremos nosotros con seguridad si es de esa creencia sincera en la cientificidad del Derecho de donde surge su empeño por elevar el rango académico de los estudios jurídicos o si, por el contrario, la invocación de la idea de ciencia no es más que una estrategia retórica para alcanzar dicho objetivo. En un discurso pronunciado en 1886 durante la conmemoración del 250 aniversario de la fundación del Harvard College, Langdell insiste en que «el Derecho es una ciencia», y añade: « $\mathrm{Si}$ el Derecho no fuera una ciencia, más le valdría a la universidad hacer honor a su propia dignidad renunciando a su enseñanza. Si no fuera una ciencia, entonces es una especie de artesanía, y la mejor manera de aprenderla será sirviendo como aprendiz de alguien que la practique. Pero si fuera una ciencia, entonces difícilmente podrá discutirse que se trata de una de las más nobles y difíciles de entre las ciencias, y que precisa toda la luz que el más ilustrado centro del saber pueda arrojar sobre ella». En este sentido, la contribución de Langdell al fortalecimiento institucional de la enseñanza del Derecho fue muy notable: entre otras cosas, elevó los estándares para la admisión de estudiantes, introdujo un riguroso sistema de exámenes, sentó las bases de la mayor biblioteca jurídica del mundo, reclutó a un claustro de profesores de excelente calidad, y creó la figura del catedrático profesional de Derecho ${ }^{53}$. En suma, Langdell creó el

${ }^{53}$ Antes de Langdell, los profesores de Derecho, incluidos los que enseñaban en la universidad, eran jueces y abogados dedicados a la docencia sólo como actividad secundaria. Como Decano de Harvard, Langdell contrató a James Barr Ames, un brillante licenciado recién salido de la facultad y sin ninguna 
modelo de las facultades de Derecho americanas como las grandes instituciones educativas que antes he descrito. Pero no son estas reformas «institucionales» las que ahora nos interesan, ni tampoco son ellas la razón principal por la que este personaje ha pasado a la historia $^{54}$. La verdadera «revolución» de Langdell hay que buscarla en los contenidos y métodos docentes.

Langdell no sólo reaccionó contra el enfoque «artesanal» del modelo Litchfield, sino también y especialmente contra el modo dominante en la enseñanza universitaria del Derecho de su época, que como hemos visto era la lección magistral al estilo de Blackstone. Él había llegado a la conclusión de que el estudio científico del Derecho debía consistir en el dominio de un número relativamente reducido de principios o doctrinas básicas, y de que la vía rápida y segura de alcanzar ese dominio era el análisis de una serie de «casos» o sentencias judiciales cuidadosamente seleccionadas, en las que esos principios y doctrinas toman cuerpo. En consecuencia, el método de enseñanza del Derecho debía centrarse en el estudio de esos casos: el «case method».

También en este terreno estrictamente de la docencia llevó Langdell a la práctica sus ideas: como profesor de Derecho de Contratos elaboró una compilación sistemática de las principales sentencias de los tribunales de apelación ingleses y americanos en esta materia, compilación que publicó en 1871 con la intención de que sirviera como instrumento de estudio para sus alumnos. Había nacido el primer «casebook» ${ }^{55}$.

experiencia profesional como abogado: para Langdell, la enseñanza del Derecho, en cuanto ciencia, debía ser impartida por expertos en esa disciplina, independientemente de que hubieran ejercido o no la profesión.

${ }^{54}$ No cabe duda de que la orientación «práctica» de la enseñanza del Derecho en Estados Unidos sigue siendo hoy mucho más marcada que en países como España. No por casualidad las facultades de Derecho americanas todavía se denominan «escuelas» de Derecho, al igual que las demás escuelas de enseñanzas profesionales (Medicina, Empresariales, Ingenieros...), independientes de los «Departamentos» de la universidad. Y es que el objetivo primordial no es tanto cultivar intelectualmente una disciplina «científica», cuanto preparar profesionales con una buena formación técnica para el ejercicio del Derecho. Como señala Twining (op. cit., supra nota 19), Langdell sortea la posible tensión entre estos dos objetivos al afirmar, como veremos, que «el verdadero jurista» es aquél que domina los principios jurídicos de tal manera que es capaz de aplicarlos «con constante facilidad y seguridad a la madeja siempre enredada de los asuntos humanos».

${ }^{55}$ En el «Prefacio» de esta obra, Langdell escribe uno de los párrafos más citados a la hora de explicar los orígenes y el espíritu del «case method»: «El Derecho, considerado como una ciencia, consiste en ciertos principios o doctrinas. Lo que define a un verdadero jurista es poseer la maestría suficiente sobre estas doctrinas como para ser capaz de aplicarlas con constante facilidad y seguridad 
Langdell creía además que la docencia debía desarrollarse de tal manera que los alumnos «pudieran sacar mayor aprovechamiento de la asistencia a clase que dedicando el tiempo al estudio privado». En efecto, una vez que los estudiantes disponían de un libro de casos, el paso siguiente tenía que ser el abandono de la tradicional conferencia o lección magistral: se podía exigir a los estudiantes que leyeran cuidadosamente los casos previamente asignados para cada clase, de manera que, en lugar de «tomar apuntes», el tiempo de ésta se dedicara a la discusión colectiva de esos casos bajo la dirección del profesor. Éste debería orientar el debate planteando a los estudiantes las preguntas pertinentes para, entre todos, llegar a las conclusiones «correctas». Esta forma de dar clase se conoce en las facultades de Derecho americanas bajo el nombre, un tanto pretencioso, de «método socrático».

Estas tres novedades («case method», «casebook», y «socratic method») encontraron una fuerte resistencia durante bastantes años, pero poco a poco fueron imponiéndose, y hacia la tercera década del presente siglo el case method (nombre que, en sentido amplio, englobaría a las tres) era ya practicado en la mayoría de las facultades de todo el país ${ }^{56}$. Hoy en día puede decirse que el

a la madeja siempre enredada de los asuntos humanos; es por ello que adquirir esa maestría debe ser la tarea de todo buen estudiante de Derecho. Cada una de estas doctrinas ha llegado a su estado actual a través de una lenta progresión; es decir, se trata de un crecimiento, que en muchos casos se extiende durante siglos. Por lo general, este crecimiento puede ser rastreado a través de una serie de casos; y la forma con mucho más rápida y mejor, si no la única, de dominar eficazmente la doctrina es estudiando los casos en que ésta se encarna. Pero los casos que son útiles y necesarios para este propósito en la actualidad guardan una proporción sumamente pequeña en relación con todos los que se han registrado. La inmensa mayoría son inútiles, o peor que inútiles, para cualquier propósito de estudio sistemático. Por otra parte, el número de doctrinas jurídicas fundamentales es mucho menor de lo que comúnmente se cree; las muchas guisas diferentes en que la misma doctrina está constantemente haciendo su aparición, y la gran medida en que los tratados jurídicos son una repetición unos de otros, son causa de muchos malentendidos. Si estas doctrinas pudieran ser clasificadas y dispuestas de forma tal que cada una pudiera encontrarse en su lugar apropiado, y no en otro, dejarían de ser formidables en numero». Langdell, Christopher Columbus, A Selection of Cases on the Law of Contracts, viii (1871).

${ }^{56}$ A esta expansión sin duda contribuyó decisivamente el hecho de que el case method irradiara desde Harvard Law School, que por entonces ejercía desde hacía ya años un claro liderazgo entre las facultades de Derecho americanas, que por otra parte en 1871 eran sólo 31. Precisamente los años de expansión del case method coinciden con un período de rápido fortalecimiento de la enseñanza universitaria del Derecho: entre 1870 y 1900 el número de facultades de Derecho pasó de 31 a 102. La mayoría de las facultades de nueva creación siguieron también el modelo de Harvard. 
modelo de enseñanza del Derecho dominante en Estados Unidos sigue siendo el inspirado por Langdell. En realidad -y pese a las muchas críticas y debates en torno al case method, intentos de reforma y propuestas de alternativas pedagógicas ${ }^{57}$-, después de más de un siglo apenas cabe hablar de cambios verdaderamente radicales en la enseñanza del Derecho en este país. Las ideas de Langdell, tanto las relativas al diseño institucional de las facultades de Derecho como las de su modelo docente, configuraron lo que ha dado en llamarse una «ortodoxia» ${ }^{58}$ que, con la inestimable ayuda de Harvard como su principal guardián, todavía hoy sigue gozando de muy buena salud.

Sentado esto, es necesario advertir de inmediato que el case method, tal como lo concibió Langdell, sí ha experimentado algunos cambios importantes. Si, generalizando mucho, cabe hablar de algo así como una «línea de evolución» del case method, ésta podría sintetizarse como la de una cierta tendencia hacia la «sustantivización», o al menos hacia la moderación de su formalismo inicial ${ }^{59}$.

${ }^{57}$ El case method ha sido cuestionado sobre todo en dos «oleadas» críticas: la protagonizada por los realistas en los años 20 y 30 , y la de los movimientos que agitaron a toda la enseñanza universitaria durante los años 60. Pero la discusión en torno a la enseñanza del Derecho, con mayor o menor virulencia, ha sido una constante en la cultura jurídica americana hasta nuestros días. Hoy podría hablarse de una tercera oleada de críticas que recupera muchos de los rasgos de las dos anteriores. Me refiero a la encabezada por muchos de los miembros del movimiento llamado «Critical Legal Studies». Sobre los ataques de los realistas, véase Llewellyn, Karl, «On What Is Wrong with So-Called Legal Education», 35 Columbia Law Review 653 (1935); «The Current Crisis in Legal Education», 1 Journal of Legal Education 215 (1948); The Bramble Bush. On Our Law and Its Study, 1930, 2. ${ }^{\text {a }}$ ed., 1951, Oceana, New York, pp. 192; Frank, Jerome, «Why Not a Clinical Lawyer-School», 81 University of Pennylvania Law Review 908 (1932); Green, Leon, «A New Program in Legal Education», 17 American Bar Association Journal 299 (1931); Lasswell, Harold; McDougal, Myres, «Legal Education and Public Policy: Professional Training in the Public Interest», 53 Yale Law Journal 203 (1943). Sobre las críticas de «Critical Legal Studies», véase Kennedy, Duncan, Legal Education and the Reproduction of Hierarchy, Afar, Cambridge, 1983; Klare, Karl, «The Law School Curriculum in the 1980's: What's Left?», 32 Journal of Legal Education 336 (1982); Gordon, Robert, «Critical Legal Studies as a Teaching Method, Against the Background of the Intellectual Politics of Modern Legal Education in the United States», 1 Legal Education Review 59 (1989).

${ }^{58}$ Grey, Thomas, «Langdell’s Orthodoxy», 45 University of Pittsburgh Law Review 1 (1983).

${ }^{59}$ Debo pedir disculpas de antemano al lector por el uso descaradamente ambiguo e impreciso que hago a continuación de etiquetas tan manidas como «formalismo», «realismo», «carácter sustantivo», «positivismo», etc. Soy consciente de las dificultades que encierra una utilización tan simplificada de este tipo de 
Como espectadores europeos formados en la tradición continental, a primera vista las reformas de Langdell quizá no nos parezcan -al menos para su época- la expresión de un enfoque excesivamente «formalista» del Derecho y de su estudio, sino más bien todo lo contrario. Al fin y al cabo, el case method pone el énfasis en las sentencias concretas de los jueces más que en las reglas generales y abstractas del Derecho legislado; en el estudio de fuentes primarias en lugar de manuales doctrínales; en la discusión participativa en las aulas en lugar de la pasividad y el dogmatismo de la lección magistral; en la formación metodológica y en la capacidad de argumentación jurídica en lugar de la simple memorización de información acerca de reglas y doctrinas previamente sistematizadas. Y, sin embargo, Langdell ha sido y sigue siendo considerado en América el principal representante de ese enfoque acerca del Derecho vagamente etiquetado como «formalista». Para autores como Holmes y como Frank, Langdell simbolizaba explícitamente la encarnación del «enemigo». ¿Cómo se entiende esto?

En primer lugar, creo que conviene introducir aquí, a modo de recordatorio, una advertencia general acerca de algo que es tan sabido como frecuentemente olvidado. La cultura jurídica americana ha sido siempre -y no sólo a partir de los realistas- muchísimo más «sustantiva»o antiformalista que la europea continental, e incluso más también que la inglesa ${ }^{60}$. En comparación

términos, que a menudo confunde más que aclara las cosas y está en la raíz de numerosos malentendidos y de bizantinas discusiones sobre palabras. Sin embargo, ni es éste el lugar ni dispongo ahora de espacio para introducir rigurosas distinciones analíticas en mi discurso, que no quiere ser más que una descripción general de algunas ideas muy básicas en relación con la enseñanza del Derecho, sin pretensiones teóricas «mayores». En el nivel de análisis en que aquí me sitúo, emplearé pues estos términos como lo que en realidad son, simples etiquetas o «símbolos» que sirven para evocar posturas o corrientes muy diversas y complejas en las que ahora no voy a entrar, ni creo que sea aquí estrictamente necesario hacerlo. Dejo en libertad al lector para que interprete esas expresiones según la acepción que más le plazca, ya que a todas ellas me refiero en general cuando aquí las uso: sacrificando el rigor en aras de la brevedad, a mí me basta con que el lector vaya viendo «por donde van los tiros».

${ }^{60}$ Dejando de lado la etapa colonial, la historiografía jurídica americana suele emplear una periodización tripartita introducida por Hewellyn en The Common Law Tradition: la etapa que va de la Revolución a la Guerra Civil (período «antebellum»), la etapa que transcurre entre la Guerra Civil y el final de la Primera Guerra Mundial o la aparición del realismo jurídico (período «clásico»), y la etapa actual (a la que podríamos llamar «post-realista»).

Durante la primera de estas etapas (circa 1776-1870), caracterizada por lo que Llewellyn llamó el «Grand Style», se arrastra todavía el trasfondo iusnaturalista y populista de la Revolución. Se trata de una «era formativa» (véase Pound, 
con Europa la variable, llamémosla así, «formalismo / realismo» está en América mucho más «desplazada» en bloque hacia el segundo de estos polos, de manera que lo que a nosotros puede parecernos una posición más bien "sociologista», "antinormativista», "realista», o como se la quiera llamar, en América lo es mucho menos; y viceversa, allí tacharían de «formalista»o «positivista» a posturas que para nosotros no lo son tanto (esto último es un poco lo que ocurre con Langdell). Uno nunca termina de acostumbrarse del todo a la paradoja de que sea en un país con este tipo de «cultura» o «tradición» jurídica donde precisamente se desarrollaran las críticas más feroces contra el formalismo: al leer los textos de los realistas uno no puede dejar de pensar que donde verdaderamente muchas de esas críticas serían pertinentes es en

Roscoe, The Formative Era of American Law, 1938) dominada por una concepción «instrumental» más que «formal» del Derecho y del razonamiento jurídico: como escribe Llewellyn, por «formativa» Pound tenía en mente «la creación efectiva de la doctrina que se necesitaba, mediante selección, mediante modificación, mediante invención». El «Grand Style» de esta época aspiraba a reconciliar particulares nociones de «equity» y de «policy», según Llewellyn, se aceptaban los precedentes sólo después de haberlos contrastado, por un lado, con «principios» jurídicos (entendidos «no como meras herramientas para dotar a las reglas de un orden a gran escala» sino como «grandes generalizaciones que deben proporcionar sentido además de orden»); y, por otro lado, con razones de «policy» («en términos de consecuencias previsibles de las reglas»). En suma, el «Grand Style» del Common Law es «una forma de renovación continua del Derecho», «una armonización operativa de visión y tradición, de continuidad y crecimiento, de maquinaria y propósito, de medida y necesidad» (Llewellyn, Karl, The Common Law Tradition. Deciding Appeals, Little, Brown and Co., Boston, 1960 , pp. 565, en pp. 36-38).

Durante la segunda etapa (circa 1870-1920), según Llewellyn, el «Grand Style» se sustituye por el «Formal Style», cuyo «padre» podría decirse que es Langdell. Pero en Estados Unidos el formalismo jurídico «clásico» (que triunfó más tarde, y durante menos tiempo) nunca llegó a alcanzar los extremos que adquirió en Europa continental. Como escribe Robert Gordon, nunca hubo en América tal cosa como «un formalismo puramente lógico-deductivo», o «mecánico», o una «jurisprudencia de máquina de monedas» («slot-machine jurisprudence»). «Pocos incluso entre los juristas clásicos de Common Law llegaron a ser formalistas cien por cien en el sentido del positivismo o la pandectística de los países de Derecho Civil; nosotros estamos demasiado apegados al caso y a la situación concreta como para eso. Los juristas del Common Law de los tiempos pre-realistas ciertamente habrían insistido en que la suya era una jurisprudencia de principios, y se hubieran sorprendido ante la idea de que pudiera no serlo» (Gordon, Robert, op. cit., supra nota 57, en p. 1-2).

En cuanto a una comparación con la cultura jurídica inglesa, el objetivo principal de todo el libro de Atiyah y Summers al que tanto he recurrido en este trabajo es precisamente demostrar la tesis de que el Derecho y la cultura jurídica de Estados Unidos son marcadamente «sustantivos», en comparación con el carácter mucho más «formal» de la tradición jurídica inglesa. 
Europa, y no (o mucho más que) en Estados Unidos. Si Langdell era para Holmes «el mayor teólogo jurídico vivo», ¿qué no diría de la «escuela de la exégesis» o de la «jurisprudencia de conceptos»? ${ }^{61}$. Por otra parte, no debemos dejarnos seducir demasiado por el tinte «judicialista» que se podría percibir en una orientación que, como el case method, gira en torno a las sentencias de los tribunales. Como ya había dicho Bentham años atrás, en el sistema del «Common Law» los jueces elaboran las normas «como lo haría un hombre para con su perro: cuando se quiere impedir que el perro haga algo que el dueño no quiere, se espera hasta que lo haga, y entonces se le castiga por ello» ${ }^{62}$. Así, en un país de «Common Law» como Estados Unidos, si puede triunfar un enfoque de tipo formalista, éste ha de ser sobre todo un «formalismo jurisprudencial», y cualquier orientación de carácter «judicialista» no tiene exactamente las mismas connotaciones antiformalistas que tendría en la Europa continental.

Una vez situados en este contexto, hay que decir que la concepción del case method de Langdell responde efectivamente a una visión formalista. «Formalista» al menos en dos sentidos. En primer lugar, y como se desprende claramente del largo pasaje que antes he reproducido $^{63}$, el estudio de sentencias judiciales concretas no es más que la vía para extraer y construir, a partir de ese material en bruto y desordenado, un sistema lógicamente consistente de principios y doctrinas generales, que es en lo que verdaderamente consiste el Derecho, no siendo esas sentencias más que sus manifestaciones particulares. Como dice Holmes, «el ideal jurídico del Sr. Langdell, la finalidad de todos sus esfuerzos, es la elegantia juris o la integridad lógica del sistema en cuanto sistema. Él es, quizá, el mayor teólogo jurídico vivo. Pero, como teólogo, no está tan preocupado por sus postulados como por mostrar que las conclusiones derivadas de ellos permanecen ligadas entre sí» ${ }^{64}$. El case method de Langdell implica pues la sistema-

${ }^{61}$ Por supuesto, la paradoja a la que me estoy refiriendo se podría disolver dándole la vuelta al argumento: precisamente esa cultura jurídica «sustantivista» de Estados Unidos es el caldo de cultivo idóneo para que surjan movimientos como el realista, que en contextos jurídicos mucho más «cerrados» como el europeo difícilmente podían haber cuajado o haber tenido el mismo peso y alcance.

${ }^{62}$ La cita de Benthamestá recogida de Friedman, Lawrence (op. cit., nota 2, en p. 108), quien a su vez la recoge de Cook, Charles M., The American Codification Movement: A Study of Antebellum Legal Reform (1981), p. 75.

${ }^{63}$ Véase supra, nota 55.

${ }^{64}$ Holmes, Oliver Wendell, ((Review of Langdell's A Selection of Cases on the Law of Contracts», 14 American Law School Review, 233 (1880). 
tización del Derecho mediante un análisis neutral, donde las ideas de orden, sistema, taxonomía y simplicidad juegan el papel central. Haciendo abstracción de las circunstancias concretas que se deciden en el contexto particular de cada caso, el estudio de una sentencia debía dirigirse más bien al principio jurídico subyacente a su «ratio decidendi». Los principios así extraídos podrían después aplicarse casi mecánicamente («con constante facilidad y seguridad», decía Langdell) a nuevas situaciones, debiendo el juez respetar escrupulosamente la doctrina del precedente («stare decisis»). A los pocos casos particularmente importantes que debían incluirse en un «casebook» se les atribuía pues un carácter normativo general que los hacía susceptibles de un tratamiento casi tan «formalista», aunque fueran sentencias judiciales, como el que daría un jurista continental de aquella época a los artículos de un código ${ }^{65}$.

En segundo lugar, el case method diseñado por Langdell era «formalista» en el sentido de que aislaba herméticamente el estudio del Derecho tanto respecto del «sucio mundo del ejercicio profesional» ${ }^{66}$ como de las demás disciplinas sociales. Esto es consecuencia de su visión del Derecho como «verdadera ciencia», que debía afirmar su autonomía, su «pureza» en el sentido del positivismo jurídico más estrecho ${ }^{67}$. El Derecho sólo consta de principios y doctrinas jurídicas, y en las facultades de Derecho la dieta exclusiva de los estudiantes debía estar compuesta por los casos en que éstas aparecen. La ciencia política, la historia, la sociología o la economía debían confinarse en otros

${ }^{65}$ Digo «casi» porque en todo caso, como señala Twining, la variedad de las fuentes utilizadas por el case method siempre permitiría dejar un cierto margen para un «elemento de preferencia, y por tanto de creación silenciosa, soterrada». Además, el tratamiento de los casos en su secuencia cronológica confiere inevitablemente una cierta concreción y perspectiva histórica al estudio de las reglas jurídicas. Véase Twining, William, op. cit., nota 19, en p. 13 y p. 15. No obstante, aunque Langdell dispone los casos en orden cronológico, lo importante para él es mostrar su secuencia lógica más que cronológico-histórica: se trata de presentar una «línea de casos» bien seleccionados que expresan consistentemente un mismo principio o doctrina, desatendiendo (por «inútiles, o peor que inútiles») otros casos que pudieran contradecir dicha estructura.

${ }^{66}$ La frase es de Friedman, enfatizando la actitud negativa de Langdell hacia la enseñanza del Derecho como mero aprendizaje de una técnica profesional, como antes he señalado. Véase Friedman, op. cit., nota 52, en p. 289.

${ }^{67}$ También Holmes denuncia este hermetismo de Langdell: «Él sólo está por la lógica y odia toda referencia a cualquier cosa que esté fuera de ella, y sus explicaciones y conciliaciones de los casos habrían asombrado a los jueces que los decidieron». Véase Howe, Mark de Wolfe (ed.) Holmes-Pollock Letters, 17 (1941). 
departamentos de la universidad. La experimentación empírica y cualquier referencia 
al entorno social quedaban desterradas de la facultad de Derecho. Dicho con otras palabras, Langdell es el padre del llamado «paradigma del Derecho en los libros» ${ }^{68}$.

\section{b) El «case method» en la actualidad}

Me he detenido a explicar la orientación del case method en su versión original, la de Langdell, no simplemente como curiosidad histórica. En la medida en que, como he dicho, la «ortodoxia» de Langdell sigue fundamentalmente vigente, también siguen siendo pertinentes muchas de las críticas a su formalismo que le dirigieron los realistas, o las que más o menos vagamente inspiradas en éstos se le dirigen todavía hoy. Ahora bien: que la «revuelta contra el formalismo» protagonizada por los realistas estuviera lejos de triunfar plenamente no significa que sus críticas a Langdell no dejaran huella alguna. No puedo detenerme aquí en esas críticas, pero sí debo entrar a describir con algo más de detalle cómo funciona hoy el case method después del -para algunos todavía insuficiente- impacto del realismo, que sin duda sí ha conseguido como mínimo moderar su formalismo.

Una de las modificaciones más llamativas que ha experimentado el case method después de los años treinta afecta a los instrumentos empleados en la enseñanza. Los «casebooks», que antes sólo contenían sentencias de los tribunales de apelación ${ }^{69}$, ahora suelen además incluir, entre otros materiales, comentarios y preguntas planteadas al estudiante por el propio compilador, fragmentos de las actuaciones del proceso en primera instancia, textos legales

${ }^{68}$ En el discurso de 1886, antes aludido (supra, p. 71), Langdell afirmaba que «el Derecho puede aprenderse y enseñarse en la universidad mediante libros impresos», que «los libros impresos constituyen la fuente definitiva de todo el conocimiento jurídico», y que por lo tanto «todo estudiante que pretenda adquirir algún dominio del Derecho como ciencia debe recurrir a estas fuentes»; y añadía: «la biblioteca es el taller de trabajo propio de los estudiantes y de los profesores por igual; es para nosotros todo lo que los laboratorios de la universidad son para los químicos y los físicos, todo lo que el museo de historia natural es para los zoólogos, todo lo que el jardín botánico es para los botánicos». No hay que olvidar que los «libros impresos» a que se refiere Langdell no son otra cosa que los «casebooks», donde no se debía recoger más que casos jurídicos.

${ }^{69}$ Es un lugar común la crítica contra la «appelate court-itis» de la cultura jurídica americana. Para una versión ya clásica de esta crítica, véase por ejemplo la de Frank: Law and the Modern Mind, 1930 (ed. de 1963, reimp. de 1970, Peter Smith, Gloucester, Ma, en pp. xi-xix); Courts on Trial, 1949 (ed. 1973), Princeton University Press, Princeton, NJ, esp. capitulo XV, «The Upper Court Myth», pp. 222-224); «Cardozo and the Upper-Court Myth», 13 Law and Contemporary Problems 369 (1948). 
(obligada respuesta al enorme incremento de la proporción del Derecho legislado respecto del jurisprudencial desde los años de Langdell hasta hoy), formularios, fragmentos de libros o artículos jurídicos escritos por académicos y, lo que es más importante, textos y notas del propio autor o de otros especialistas relativos a aspectos sociológicos, económicos, filosóficos, históricos, etc. relevantes para el caso en cuestión. El tradicional «casebook» ha sido pues sustituido, en muchos casos, por publicaciones que suelen llevar el más descriptivo título de «cases and materials». La incorporación al «casebook» de otras disciplinas distintas del Derecho puede entenderse como el resultado directo de la influencia ejercida por la jurisprudencia sociológica y el realismo jurídico ${ }^{70}$.

En general, el carácter cerrado de la enseñanza del Derecho como ciencia autónoma ha dado paso a una orientación cada vez más interdisciplinar. Síntoma de ello es la proliferación más o menos reciente de escuelas o movimientos que defienden la introducción de diversos enfoques acerca del Derecho y de su docencia desde o en conexión con otras disciplinas. Me refiero a los movimientos que suelen bautizarse con el nombre de «Law and...»: «Law and Society», «Law and Economics», «Law and Literature», " Law and Psychology», etc. ${ }^{71}$ Estas tendencias han logrado con-

${ }^{70}$ De todas formas, los libros de «cases and materials» siguen estando muy lejos de lo que sería un «manual» como los que se utilizan en España. En Estados Unidos los manuales apenas existen: en las asignaturas de dogmática jurídica se emplean los mencionados «casebooks» (con o sin otros «materials»), y en los demás cursos se reparte a los estudiantes un voluminoso paquete de «readings»: una selección de fotocopias de artículos o fragmentos de libros encabezados por un índice o programa con un calendario de lecturas para discutir en cada sesión. Una posible explicación de la escasez de manuales es que, desaparecida la lección magistral, los materiales que elaboran los profesores para sus disertaciones, que suelen ser el germen de los manuales, dejan de redactarse, y esas energías se emplean en la preparación de libros de casos. Ni siquiera es corriente que se utilicen monografías completas -no ya manuales- como texto básico para un curso. También la publicación de monografías es proporcionalmente escasa en América. No es que en las facultades de Derecho americanas se escriba menos, sino que se publica casi exclusivamente en revistas; aunque eso sí, no es muy raro que los artículos superen las 200 páginas, y un artículo de unas 100 páginas entra todavía dentro de lo normal.

${ }^{71}$ En este carácter multidisciplinar de la enseñanza del Derecho, y en la aparición de estos nuevos movimientos (a los que habría que añadir, más recientemente, "Critical Legal Studies», «Feminist Jurisprudence» y "Critical Race Theory») yo creo que algo han debido influir algunos factores «institucionales» de los que he hablado en la primera parte de este trabajo, como la ausencia de departamentos internos en las facultades de Derecho o, sobre todo, la exigencia de una formación previa en el College: los estudiantes llegan a la facultad de Derecho familiarizados ya con algunas de 
estas otras disciplinas, e 
solidar su presencia -unas más que otras- en el curriculum de cursos ofrecidos por muchas facultades, y aunque siguen situadas en la periferia más que en el centro de la enseñanza del Derecho, su influencia también se ha dejado notar en los contenidos y en el estilo docente algo más abierto a consideraciones «extrajurídicas» que presentan hoy los estudios dogmático-jurídicos que tradicionalmente ocupan el centro (los análisis centrados en la llamada «legal doctrine») $)^{72}$.

De todas formas, el énfasis de la enseñanza del Derecho sigue recayendo en el estímulo y desarrollo de las «facultades», «habilidades» o «técnicas» que caracterizan propiamente el trabajo del «jurista». En América suele emplearse una expresión que sintetiza el sentir generalizado acerca de qué es lo que deben enseñar las facultades de Derecho: a «pensar como juristas». La idea es bien sencilla: a través del case method y de la «discusión socrática» lo que se busca es proporcionar una buena formación metodológica, más que la acumulación memorística de una información enciclo-

incluso los profesores pueden verse inclinados a introducir en su docencia e investigación aquellas disciplinas en las que ellos se especializaron durante el College y cuyo estudio quizá nunca abandonaron del todo (presumiblemente, muchos de los miembros de «Law and Economics» se habían graduado con un «perfil» en economía, los de «Law and Literature» en literatura, los de «Law and Society» en sociología, etc.).

${ }^{72}$ En América, la expresión «legal doctrine» no alude, como su traducción literal nos puede llevar a pensar, a la «doctrina jurídica» entendida estrictamente como la doctrina elaborada por los tratadistas: «legal doctrine» significa simplemente Derecho positivo, o como suelen decir los americanos, «black-letter law». Ocurre que en un sistema de Common Law, de Derecho fundamentalmente judicial (al menos en sus orígenes) como es el americano, el «Derecho positivo» está formado básicamente por las reglas y «doctrinas» elaboradas por los jueces y tribunales en la fundamentación de sus sentencias. Esa «doctrina legal», lentamente construida a través de sucesivas sentencias de diversos tribunales, ha de entenderse pues en un sentido muy parecido, si no idéntico, al que empleaba nuestra legislación procesal al recoger como causa de casación la «infracción de doctrina legal». Ahora bien: en América la frontera entre lo que aquí llamaríamos «dogmática jurídica» y su propio objeto de estudio está aún más difuminada que en Europa continental, ya que, como hemos visto, esas doctrinas jurisprudenciales se ven a menudo enriquecidas en su paulatino desarrollo por las interpretaciones y matices introducidas por académicos y juristas de todo tipo, que suelen ser recogidos por los tribunales. Así, la «doctrina» del enriquecimiento injusto es Derecho positivo, plasmado en casos jurisprudenciales y aplicable por los jueces en futuros casos, y es a la vez «doctrina jurídica» en el sentido de que en su construcción también han participado los dogmáticos del Derecho desde las universidades. Quizá ahora se entienda mejor el sentido del término «doctrina» empleado por Langdell en el pasaje antes citado, y la definición de esa voz ofrecida por el Black's Law Dictionary (abridged 5th edition, West Publishing Co., St. Paul, Minn., 1983): «una regla, principio, teoría o dogma del Derecho; como la doctrina de la absoción [merger], la doctrina de la relación, etc.». 
pédica acerca de reglas y doctrinas jurídicas ${ }^{73}$. El objetivo primordial no es tanto «enseñar normas», sino enseñar a plantear, analizar, comparar, construir y evaluar concretas situaciones fácticas y argumentos y decisiones jurídicas (sobre todo judiciales, pero también legislativas), y a «proyectar» líneas de casos y de legislación sobre situaciones nuevas ${ }^{74}$. Se trata pues de fortalecer ante todo la capacidad de análisis y de razonamiento jurídico, así como la de su expresión oral y escrita. Suele decirse además que el case method, al menos tal y como se concibe hoy, está «orientado a la resolución de problemas» («problem-solving») por parte de los estudiantes, más que a la recepción pasiva de la doctrina: tanto o más que conocer los contenidos de soluciones concretas (que pueden variar de uno a otro Estado, de una a otra sentencia o línea jurisprudencial), los estudiantes deben aprender a discernir por sí mismos dónde están los problemas relevantes, cómo surgen y mediante qué procesos jurídicos los tribunales, los legisladores

${ }^{73}$ A veces se ha criticado al case method porque «va demasiado lejos» en esa orientación casi exclusivamente metodológica, descuidando en exceso el aprendizaje de reglas. Yo no estoy muy de acuerdo con este tipo de reproches. Por supuesto que un jurista también debe saber normas, pero no es necesario que sean tantas como las que suelen inyectarse a presión en las memorias de nuestros estudiantes y opositores. Para algo están los libros, y lo verdaderamente importante es aprender a manejarlos, saber qué se puede hacer con las normas que contienen, y sobre todo cómo hacerlo. Quizá haya habido casos excepcionales en que se haya incurrido en excesos, pero mi impresión es que en general las facultades de Derecho americanas cumplen sobradamente con la función de «enseñar normas» en la medida necesaria: las reglas y principios básicos sí se aprenden, y la memoria sigue siendo una de las aptitudes esenciales que precisa un estudiante de Derecho (hasta el punto de que, por más que a nosotros nos sorprenda, también es posible escuchar en América críticas precisamente en el sentido contrario: en el de que la enseñanza del Derecho sigue siendo excesivamente memorística).

Por otro lado, la tarea de inculcar normas resulta bastante más complicada en un país como Estados Unidos, donde una facultad de Derecho «nacional» difícilmente puede aspirar a enseñar el Derecho de todos y cada uno de los cincuenta Estados, y porque se trata de un sistema de Common Law, donde una buena parte del Derecho no está recogida en códigos o textos legales más o menos sistematizados, sino que ha de ser rastreada a partir de sentencias judiciales que expresan reglas o principios mucho más imprecisos y flexibles. Mediante el case method, el estudiante aprende sobre todo a extraer por sí mismo esas reglas y doctrinas, cuyo resultado conforma un cuerpo de Derecho quizá no muy voluminoso, pero que es el suyo propio, el producto en buena medida de surazonamiento y de su esfuerzo personal. Quizá hubiera aprendido más cosas si el profesor se las hubiera dado ya hechas, pero las cosas se aprenden mejor mediante la experiencia de hacerlas uno mismo.

${ }^{74}$ Véase Atiyah, P.S., Summers, R.S., op. cit. en nota 1, p. 391; Farnsworth, E. Allan, An Introduction to the Legal System of the United States, Oceana Publications, New York, 2. ${ }^{a}$ ed., 1983, pp. 172, en p. 17. 
o los abogados intentan resolverlos. Interesa, en suma, que los estudiantes aprendan a hacer preguntas casi más que a saber las respuestas.

En los tiempos de Langdell, este énfasis en la capacidad de razonamiento se entendía sobre todo en el sentido de «razonamiento lógico». Entre los defensores actuales del case method todavía quedan muchos que mantienen esa fe en la suficiencia de la «razón formal» y en la aplicabilidad mecánica de los principios extraídos de los casos, con la proscripción de cualquier consideración valorativa o argumentación de carácter sustantivo. Ocurre que, invocando al prestigioso nombre del case method, se han defendido y se defienden interpretaciones o aplicaciones del mismo más o menos «formalistas», más o menos «sustantivas». Cabe decir en líneas generales que, como sostienen Atiyah y Summers, el case method se ha «sustantivizado» mucho, aunque mi impresión es que no tanto como lo pintan estos autores ${ }^{75}$. De todas formas, hay que reconocer que en la actualidad el empleo del case method ha abierto sus puertas al razonamiento sustantivo, a los argumentos materiales en términos de «policies», a la justificación de carácter social, económico y a veces incluso político y moral. Para algunos, esta «apertura» resulta todavía insuficiente. En todo caso -esto es lo que a nosotros más nos interesa aquí- en términos comparativos con la situación española el case method practicado hoy en América es sin duda un método de enseñanza mucho menos formalista y mucho más abierto a la argumentación sustantiva que el modelo estándar de enseñanza del Derecho en España. El «policy analisis», tanto en la docencia como en la investigación, ha sido la herencia directa sobre todo de la «jurisprudencia sociológica» de Pound, y también el legado «descafeinado» que la fuerza crítica del movimiento realista consiguió dejar tras de sí en la ciencia jurídica norteamericana. Y, efectivamente, en muchos casos el Derecho ya no se enseña tanto «como un cuerpo autoritario de doctrina» cuanto «como un instrumento de "policy" política, económica y social (...). Al enseñar a sus estudiantes cómo comprender el Derecho, los docentes americanos acentúan la necesidad de buscar, por detrás de las reglas impresas, los problemas subyacentes de política social y de administración práctica» ${ }^{76}$.

${ }^{75}$ Me parece excesivo afirmar, como hacen ellos, que en el ambiente educativo americano «la fuerza justificatoria del razonamiento sustantivo de base, y no la autoridad del razonamiento formal, se convierten en el foco primario». Yo me temo que el formalismo langdelliano en las facultades de Derecho americanas, aunque de forma menos visible o con otros ropajes, sigue estando bastante más vivo de lo que creen estos autores.

${ }^{76}$ Atiyah, P.S.; Summers, R.S., op. cit., supra nota 1, en p. 391. Como 


\section{c) El "método socrático"}

Este enfoque «metodológico» e «instrumental» de la enseñanza del Derecho se pone de manifiesto sobre todo en las aulas, en la manera de conducir las clases a través del llamado «método socrático». En nuestras universidades solemos asumir con resignación la idea de que no hay manera humanamente posible de llevar a la práctica el formato de las «clases dialogadas» si tenemos delante un grupo de más de treinta estudiantes: cuando el grupo es muy numeroso, la única opción que le queda al profesor, le guste o no, es la lección magistral; la docencia a través de discusiones mínimamente rigurosas debe confinarse al marco de semi-

también señala Cavers (citado por estos autores, op. cit., en p. 390), con el case method los estudiantes «aprenden a ver el Derecho como un instrumento que está continuamente remodelando la sociedad y la economía americana. Dado que los jueces americanos, al escribir sus sentencias, tienden a discutir las "policies" políticas, económicas y sociales que tienen que ver con sus decisiones, los estudiantes que han hecho de esas sentencias la base principal de su trabajo durante tres años tienden naturalmente a pensar en la significación de reglas y decisiones jurídicas particulares en términos de "policies"».

No obstante, esta orientación hacia el «policy analysis» no está exenta de críticas, dirigidas no ya desde posiciones más o menos «formalistas», sino precisamente desde el flanco contrario. Según estas críticas, el «policy analysis» practicado en las facultades de Derecho no está suficientemente elaborado ni justificado desde un punto de vista teórico general, y tampoco está suficientemente apoyado por investigaciones empíricas concretas. Las razones de «policy» no se discuten ni argumentan seriamente, sino que se afirman sin más de forma breve y superficial, apelando a un supuesto consenso general sobre determinados valores («la eficiencia en la asignación de recursos», «la seguridad del tráfico jurídico», «la defensa de la libre competencia y de la productividad»...) o a una supuesta tendencia de desarrollo histórico ( «el crecimiento económico», «la mayor especialización del trabajo», «la creciente internacionalización de la economía»...). Estos valores y tendencias constituyen una especie de «sentido común» que se da por descontado, una especie de racionalidad funcional inmanente al ordenamiento jurídico y que supuestamente puede resolver los problemas de indeterminación lingüística del Derecho que los realistas habían puesto de relieve, pues se confía en que el jurista-tecnócrata que maneje con habilidad las técnicas del «policy analysis» será capaz de «descubrir» las soluciones socialmente óptimas para prácticamente todos los problemas jurídicos. La racionalidad técnica de esos argumentos de «policy» relativamente estandarizados y acríticamente asumidos sigue ocultando -siempre según este tipo de críticas- las «grandes cuestiones» controvertidas de carácter moral y político en sentido fuerte sobre los términos básicos del orden social. Así, el «policy analysis» puede llegar a ser visto como una puerta falsa a través de la cual se ha introducido un nuevo tipo de «formalismo», en el sentido de que se sigue manteniendo una clara distinción entre el discurso jurídico supuestamente neutral y todavía marcadamente riguroso y determinado (aunque ya no se trate de la racionalidad lógico-deductiva del formalismo clásico), y el discurso valorativo, abiertamente político-moral, que está en la raíz de las discusiones jurídicas. 
narios reducidos de estudiantes voluntarios especialmente seleccionados o motivados. En Estados Unidos, los grupos de segundo y tercer año tienen esas características: los estudiantes han elegido voluntariamente todo sus cursos (no hay asignaturas obligatorias), e incluso el profesor puede establecer -con frecuencia lo hacen- un número máximo de estudiantes y determinados requisitos de admisión para su curso (por ejemplo, haber cursado previamente cierta asignatura, o una determinada orientación de su curriculum durante el College, o conocer algún idioma extranjero...). Sin embargo, el método socrático también se utiliza, y de manera especialmente «ortodoxa», en los cursos del primer año, donde todas las asignaturas son obligatorias y los grupos son de 100 ó 150 alumnos. Sorprendente mente, el sistema funciona con relativa soltura. Esto en parte se explica porque, como ya he dicho, se trata de un colectivo de estudiantes intelectualmente más maduros, con una sólida formación durante el College, dotados de espíritu crítico y participativo, acostumbrados a expresar sus conocimientos y opiniones de manera articulada, y que han superado un proceso de selección (especialmente el LSAT) precisamente dirigido aprimar las cualidades más idóneas para este tipo de docencia; por su parte, los profesores generalmente dominan el difícil arte de la clase dialogada, que es el estilo de enseñanza que ellos mismos recibieron cuando fueron estudiantes y en el que están bien entrenados porque es el que han ejercido durante toda su carrera docente. Pero hay también otras razones «menos nobles» que explican el funcionamiento del método socrático. La participación del estudiante, y el buen nivel que se exige a sus intervenciones, se estimula de modo artificial porque el alumno sabe que de la frecuencia y calidad de sus actuaciones en clase depende en buena medida su nota final en esa asignatura, y porque muchas de las preguntas del examen tendrán que ver directamente con lo que ha ocurrido durante la discusión en el aula ${ }^{77}$. La asistencia a clase es estrictamente obligatoria, y la participación de hecho casi también.

${ }^{77}$ En las facultades de Derecho americanas los exámenes casi siempre son escritos (rasgo que parece contrastar con el estilo de la docencia); sólo hay uno o a lo sumo dos exámenes por asignatura (téngase en cuenta que la mayoría son cursos cuatrimestrales o semestrales), y suelen concentrarse los de todas las asignaturas en determinados días (no más de 10). Normalmente los exámenes constan de uno o varios casos prácticos sobre los que se plantean diversas preguntas, aunque en cursos sobre materias no estrictamente jurídico-positivas suelen consistir en la exposición de algún tema, o en comentarios de textos. Las alternativas al examen tradicional están muy extendidas, principalmente su sustitución por trabajos de investigación o el llamado «take home exam», que los estudiantes se llevan a su casa y entregan al cabo de 24 ó 48 horas. 
Muchas veces los estudiantes tienen asignado un asiento fijo y numerado en cada curso, y durante la clase los profesores tienen delante un diagrama del aula con los nombres de los estudiantes que ocupan cada asiento (a veces incluso con su fotografía), de manera que toman buena nota de cuánto y cómo interviene cada estudiante, e incluso pueden seleccionar a quién dirigir sus preguntas sin esperar a que aparezcan voluntarios. Por eso se ha criticado a veces el ambiente represivo y «de colegio» que el método socrático puede llegar a crear en las aulas. Una clase de este tipo se desarrollaría más o menos así: el profesor comienza su clase seleccionando sin previo aviso a uno de sus alumnos, a quien pide que «plantee el caso», es decir, que exponga durante unos minutos la información básica acerca de los hechos, las cuestiones jurídicas que se suscitan, la argumentación utilizada y la decisión final del juez, en relación con el caso previamente asignado para ese día ${ }^{78}$. A continuación, ese mismo estudiante es sometido a un duro interrogatorio sobre lo que acaba de decir, durante el cual el profesor le va presionando para que clarifique sus respuestas, estrechándose el cerco en torno a las cuestiones más relevantes. Tarde o temprano el alumno ha quedado contra las cuerdas y se ve incapaz de responder satisfactoriamente a una pregunta, y entonces se levantan varias manos de otros compañeros dispuestos a responderla. El profesor llama a uno de ellos y continúa con él la discusión, aunque a veces ésta se limita a aclarar el punto problemático y se reanuda el interrogatorio del primer estudiante, que puede prolongarse durante la mayor parte de la hora y media que generalmente dura una clase. Pero lo normal es que intervengan al menos una docena de protagonistas principales, y un número mucho mayor de participantes esporádicos. Con frecuencia el profesor interrumpe el debate para introducir una breve disertación

${ }^{78}$ En realidad, el método socrático empieza bastante antes de comenzar la clase: ese «planteamiento del caso» por parte de un estudiante no es otra cosa que la exposición oral, a veces simplemente leyéndolo, del «case brief» o sinopsis del caso, que todos han debido preparar de antemano por escrito en dos o tres páginas. Los «case briefs» han de seguir una técnica estándar que se enseña a los estudiantes durante los primeros días del primer curso (en la asignatura «Legal Methods» 0 «Legal Writing»), y su elaboración suele ocupar a los estudiantes buena parte de su tiempo fuera de clase (suele haber unas quince horas de clase a la semana, pero para preparar cada una de ellas los estudiantes normalmente invierten dos o tres más). No siempre es fácil hacer un buen «brief», y aprender a dominar esta técnica es importante para los estudiantes de cara a su futuro ejercicio profesional: es una de las tareas fundamentales que realizan los jóvenes abogados en las «Laws firms», o los «Law clerks» (ayudantes o pasantes) de jueces y fiscales, y también los profesionales consagrados suelen realizarla por sí mismos para su trabajo. 
sobre algún punto y continuar después la discusión. Al final, el profesor suele recopilar las conclusiones principales que «entre todos» han alcanzado, aunque hay profesores que se limitan a hacer preguntas y plantear problemas durante toda la clase, obligando a que cada estudiante extraiga por sí mismo sus propias conclusiones.

El ambiente entre los estudiantes en este tipo de clases casi siempre es muy competitivo, aunque esa competitividad se oculte a menudo bajo un frágil disfraz de cortesía y de falso compañerismo. La competitividad entre los estudiantes es uno de los rasgos más llamativos de toda la enseñanza universitaria americana, pero en la facultad de Derecho está especialmente acentuada. El propio sistema educativo la fomenta de manera más o menos abierta. Sin ir más lejos, en el complejo mecanismo de calificación de exámenes muchas veces la nota de cada estudiante se hace depender en parte de los resultados medios obtenidos por el grupo ${ }^{79}$. Otro ejemplo es la organización de las «moot court competitions», en las que todos los estudiantes de primer curso están obligados a participar. Se trata de juicios simulados ante tribunales compuestos por profesores, estudiantes veteranos, abogados y jueces locales; se forman parejas de estudiantes que se enfrentan como defensores de cada una de las partes del hipotético pleito, y hay todo un sistema de eliminatorias que culmina en una«gran final» y una pareja campeona (en las «upper-round competitions», entre estudiantes de los cursos superiores, hay incluso premios en metálico). Pero quizá la competencia más dura sea aquella que enfrenta a los mejores por el puesto más codiciado: pertenecer al consejo de redacción de la revista de la facultad, lo cual viene a ser algo parecido -salvando las distancias- a estar inscrito en aquellos «cuadros de honor» con que se premiaba a los alumnos más destacados en nuestras escuelas. Las revistas jurídicas de facultad, incluidas las más prestigiosas como la Harvard Law Review o la Yale Law Journal, tradicionalmente son editadas por un consejo formado exclusivamente por estudiantes. Pero para

${ }^{79}$ Por eso, dejar copiar a un compañero durante un examen puede acabar afectando negativamente a la nota del estudiante «generoso». Como mecanismo de «autoregulación», no está mal para evitar estos fraudes. El problema es que facilita una competitividad que obstaculiza otras formas de sana cooperación entre los estudiantes (después de una gripe un estudiante puede tener dificultades para que un compañero le preste los apuntes), e incluso llega a enrarecer las relaciones personales entre ellos. También hay que decir que ante esta situación los estudiantes suelen reaccionar organizándose espontáneamente en pequeños «grupos de estudio», donde la colaboración es muy intensa, aunque sólo con los compañeros que pertenecen a estos grupos cerrados. 
pertenecer a ese privilegiado consejo hay que tener uno de los cuatro o cinco mejores expedientes de la clase después del primer año, y / o haber superado un durísimo examen de selección organizado específicamente para este fin. En suma, los estudiantes de las facultades de Derecho americanas no estudian tanto para aprobar -ya he dicho que prácticamente todos aprueban- cuanto para sacar mejores notas que los demás y situarse así en los primeros puestos de su promoción (de ello depende además, no lo olvidemos, su salida profesional).

Pero volvamos al método socrático en las aulas. Esta atmósfera general tan competitiva explica que a veces los estudiantes levanten la mano en clase no ya con la intención de participar en una sana confrontación intelectual, sino con el deseo mal disimulado de «derrotar» y, si es posible, ridiculizar ante el profesor y ante los demás compañeros a aquel que acaba de tener una intervención desafortunada o no supo contestar a la pregunta del profesor, sobre todo si este «compañero» es uno de sus más directos rivales en el ranking de su promoción: también en las intervenciones en clase el éxito depende en parte de que se haga no ya un buen papel, sino un papel mejor que el de los demás.

Así pues, el método socrático es un arma de doble filo. Por un lado, estimula sin duda la participación activa del estudiante y le acostumbra a discutir y argumentar, a manejar en público ese estilo inquisitivo de análisis característico del abogado, cosa que difícilmente puede conseguir la lección magistral. Pero, por otro lado, puede crear en algunos estudiantes (o en muchos) un sentimiento agobiante de temor ante la posibilidad de «ser llamado» por el profesor y verse expuesto así al fracaso en público, a una cierta humillación ante el profesor y ante sus propios compañeros; la asistencia a clase puede convertirse para ellos en una experiencia diaria de tensión y angustia ${ }^{80}$, que explica la aparición de prácticas

${ }^{80}$ Sobre esta angustia que sufre sobre todo el estudiante de primero de Derecho, y en general sobre el mundo de la enseñanza del Derecho en Estados Unidos, yo recomiendo al lector cuyo interés sobre este tema no justificaría el esfuerzo de adentrarse en el resto de la bibliografía aquí anotada -o quizá ni siquiera el de leer estas páginas- la lectura de una novela. En realidad se trata de un ensayo autobiográfico «novelado», o de un diario, escrito por Scott Turow, el famoso autor de «best-sellers» tan conocidos como «Presunto Inocente». La novela se titula One-L (1977, 1. a edición de Warner Books, 1988, pp. 276), título extraído del nombre que en Harvard suele darse a los estudiantes de primer curso de Derecho (de «One-Law»; los de segundo serían «Two-L's», etc.). Turow cuenta pues su propia experiencia como estudiante de primero de Derecho en Harvard, adoptando a menudo un fuerte tono crítico. Este libro ha sido también un «best-seller», no sólo en los quioscos sino sobre todo entre los profesores y estudiantes de Derecho de todo el país: entre los primeros hay quien 
como el llamado «backbenching» ${ }^{81}$ o el «no-hassle pass ${ }^{82}$.

Una ambivalencia parecida puede detectarse en uno de los rasgos más elogiados del método socrático: el espíritu crítico que inculca a los alumnos. Efectivamente, el método socrático no sólo enseña a reconstruir paso a paso el razonamiento de los tribunales, sino también a criticarlo ${ }^{83}$. Los estudiantes deben estar preparados para emitir una opinión sobre si la decisión es correcta, y ofrecer razones para defender su postura; durante la discusión el profesor y los demás compañeros desafían al estudiante, presentándole contraargumentos que éste debe sopesar y criticar para seguir defendiendo su postura o para cambiarla. Incluso a veces el profesor plantea inicialmente el estudio de los casos adoptando el punto de vista de un juez que debe tomar una decisión careciendo de reglas o de precedentes judiciales aplicables a ese caso. Es verdad que el método socrático parece correr más el peligro de caer en la crítica gratuita y en la discusión chapucera de barra de bar, que en el extremo opuesto del dogmatismo propio de la lección magistral. Pero también hay que advertir que el método socrático es susceptible de un uso mucho más autoritario bajo la

lo cita en sus publicaciones, y entre los segundos se ha convertido en la guía extraoficial que sustituye a los catálogos de orientación de las facultades de Derecho.

${ }^{81} \mathrm{El}$ verbo «to backbench» es un ingenioso neologismo acuñado hace ya tiempo en la jerga estudiantil de las facultades de Derecho americanas. Hace alusión a la práctica de agazaparse semiclandestinamente en los bancos situados en el fondo del aula, con la esperanza de eludir así el peligro de ser llamado a intervenir. La asignación individualizada de los asientos y el diagrama del aula utilizado por el profesor intentan combatir esta práctica.

${ }^{82} \mathrm{El}$ «no-hassle pass» es una reivindicación relativamente reciente de cierto sector del alumnado. Evocando los «Miranda rights»-los derechos del detenido reconocidos en Miranda v. Arizona, 384 U.S. 436, (1966)-, consiste en el «derecho a no hablar» de un estudiante cuando es interrogado por el profesor, sin tener que dar más explicaciones sobre su negativa ni soportar el posible ensañamiento con el que éste podría presionarle para que conteste: el estudiante dice simplemente «paso» y el profesor debe dirigirse rápidamente y con toda naturalidad a otro estudiante.

${ }^{83}$ Una de las razones que explican que el case method sea un método más crítico -aparte, por supuesto, de que las cosas se discuten en clase- es el carácter necesariamente comparativo del estudio de los casos en un sistema federal como el americano: el estudiante no puede aceptar como definitiva la solución dada por el juez en el caso que tiene entre manos, porque, como dice Cavers, «el próximo caso que lea puede haber sido extraído de los repertorios de jurisprudencia de otro Estado, que adopta una posición diametralmente opuesta». No hay que olvidar que en Estados Unidos no existe un sistema jurisdiccional unitario con una estructura estrictamente jerarquizada en el que la doctrina jurisprudencial emana o se unifica desde arriba (como en el caso de nuestro Tribunal Supremo): los tribunales de los diferentes Estados pueden llegar a soluciones distintas y dotadas de firmeza sobre el mismo problema. 
apariencia abierta y flexible de la discusión con los estudiantes. De hecho, este tipo de debate ha sido criticado a veces como un juego amañado en el que de antemano la posibilidad real de ganar es de un sólo jugador: el profesor. Éste somete a los estudiantes a un interrogatorio con el que poco a poco va conduciendo al rebaño hasta su redil. El profesor está en posesión de la verdad, conoce la única respuesta correcta, y todo es cuestión de que los estudiantes lleguen «por sí mismos» (?) a esa misma conclusión, en lugar de imponérsela de manera autoritaria desde un principio. El autoritarismo intelectual queda así demagógicamente disfrazado. Al final, si alguien no entra en el redil es porque no ha sido capaz de seguir correctamente todos los pasos dados en clase, y permanecerá por tanto en el error.

\section{d) El "curriculum"}

Por último, unas palabras sobre el contenido del «curriculum» o plan de estudios. Pese a la heterogeneidad de facultades y, dentro de cada una, la variadísima oferta de cursos optativos, en la práctica se puede hablar de ciertos rasgos generales comunes que nos permiten estructurar la descripción de lo que sería el plan de estudios estándar. Esa estructura podría verse como una especie de «precipitado» de la historia jurídica (o de la historia, a secas) de Estados Unidos desde los tiempos de su primer diseñador, Langdell. Cada uno de los tres años de que consta el curriculum reflejaría un período distinto:

1) En el primer año se incluyen, con carácter obligatorio, las «grandes instituciones» o sectores tradicionales del «Common Law», el edificio básico del Derecho correspondiente al liberalismo económico de finales del XIX: «Contratos», «Torts», «Propiedad», «Procedimiento Civil» y «Derecho Penal». Como se ve, se trata básicamente de Derecho privado (con el Derecho Penal como «gendarme»). La fuente casi exclusiva es la jurisprudencia de los tribunales (el «boom» del Derecho legislado vendrá después), por lo que aquí el case method campa por sus respetos más que en ninguna otra parte. Y además, enfocado a la manera clásica, como un ejercicio de «razonamiento jurídico» entendido sobre todo en el sentido de razonamiento «formal», de sujección al precedente, de búsqueda de la «lógica interna» de cada sector de la doctrina que se plasma en una «línea de casos» bien estructurada (aquí si hay que memorizar casos emblemáticos y sus principios o doctrinas). Los argumentos de «policy» juegan un papel mucho menor. Langdell vive. 
2) En el segundo y tercer año todos los cursos son optativos (salvo el relativo a la regulación y deontología del ejercicio profesional, exigido para tal acreditación). La cantidad y variedad de las ofertas es enorme (no es raro que superen el centenar, aunque la facultad suele proponer «bloques» con un vago perfil o recomendar encarecidamente algunos cursos). En esta maraña se pueden distinguir no obstante dos grandes «tipos» de cursos. Estos dos tipos no necesariamente corresponden respectivamente al segundo y tercer año (se trata de «ganar» un cierto número de «créditos», distribuyéndose el estudiante las materias -salvo algunas «incompatibilidades»- como prefiera), aunque, dadas las costumbres que los estudiantes siguen al elegir, quizá también se puedan distinguir por años. El primer tipo (o el segundo año de carrera) sería el heredero de la jurisprudencia sociológica y del realismo jurídico, expresaría el programa «reformista» del New Deal, y mostraría la estructura burocrática y la función intervencionista y reguladora del Estado del Bienestar. Aquí se estudian cursos sobre Derecho Tributario, Derecho del Trabajo y de la Seguridad Social, Derecho Antitrust, Derecho Administrativo... es decir, Derecho público y legislado. También entraría aquí en general el estudio de la reglamentación pública del mundo económico: Derecho de sociedades («Corporations»), regulación de mercados financieros («Securities Regulation», «Acquisitions and Mergers», «Banking Regulations», «Corporate Transactions»...), comercio internacional, Derecho concursal, etc. En la docencia de estos cursos entran mucho más que antes las consideraciones de «policy».

3) Finalmente, hay un segundo tipo de cursos optativos (a menudo «seminarios») que lamentablemente se suelen relegar para el tercer año, algo más relajado porque hay que ir ya preparando el «Bar exam»y entrevistándose para un trabajo. Figuran a veces en el catálogo pensando también en quien quiera continuar con un Master o un doctorado. Se trata de cursos sobre materias tales como historia del Derecho, filosofía del Derecho, Derechos Humanos, ciencia política, teoría social, Derecho comparado, etc. Aquí se ubicarían también las «nuevas ramas» del Derecho, o el estudio de instituciones más recientes, herederas esta vez de los movimientos sociales de los años 60 (Derecho del medio ambiente, de la salud, del deporte, de los consumidores, «Public interest Law», asistencia jurídica a los necesitados -«Legal Services»-, Derecho contra la discriminación racial y sexual, Derecho urbanístico, informática jurídica, etc.), así como los cursos de «Law and...» («Law and Society», «Law and Economics», «Law and Literature», «Law and Education», «Law and Psychology», etc.) $\mathrm{y}$ 
cursos de prácticas como la llamada «clinical legal education» o la «alternative dispute resolution» (negociación, mediación, arbitraje). El enfoque de este tipo de estudios está también orientado a la "policy science», pero esta vez con un bagaje metodológico interdisciplinar mucho mayor, y a menudo se plantean cuestiones valorativas, de índole moral y política, que en los otros cursos apenas se suscitan o no se abordan abiertamente.

\section{Valoración general}

La valoración global de la anterior visión de la enseñanza del Derecho en Estados Unidos arroja un balance claramente positivo. Aunque los profesores de Derecho americanos siguen discutiendo mucho sobre estos temas, creo que en el fondo late casi siempre una cierta sensación de «complacencia» ante la calidad y ante la orientación pragmática, flexible, interdisciplinar, crítica, etc., que ha adquirido hoy la enseñanza del Derecho (la formación de «verdaderos juristas») en Estados Unidos. Para alguien venido de España, la visión puede llegar a ser aún más optimista. No se me escapa que el lector haya podido percibir cierta carencia de sentido crítico en toda mi anterior exposición, y que a medida que la iba leyendo quizá estuviera pensando, algo molesto, que yo le estaba dibujando un panorama paradisíaco de «lo bien que hacen las cosas los americanos» en claro contraste con «lo mal que las hacemos aquí». Yo no creo que América sea el paraíso, pero, en cuanto a la enseñanza del Derecho, pienso que uno puede y debe ser menos crítico con ella si la compara (es lo que he intentado hacer yo) con la situación en España, que en esto sí es, o está cerca de ser, el infierno. Piense el lector en las tres variables básicas en las que se puede establecer una comparación, y que sintetizarían mi anterior caracterización de los aspectos sustantivos (dejemos de lado los institucionales, donde la comparación es quizá más difícil) de la enseñanza del Derecho en América. Ésta es sin duda, respecto de la española: 1) más metodológica y menos memorística; 2) más sustantiva e interdisciplinar y menos formalista y cerrada; 3 ) más crítica (o participativa, o activa) y menos dogmática (o pasiva). Por supuesto que aún podría ser mucho más metodológica, mucho más sustantiva, mucho más crítica.

Precisamente, quisiera concluir recordando al lector que, pese a todo, en Estados Unidos hay un número significativo, aunque minoritario, de académicos profundamente descontentos con la enseñanza del Derecho en su país. Apenas puedo siquiera enumerar una muestra de los frentes de crítica, de los cuales sólo dos o tres 
han sido insinuados en las páginas anteriores (mi objetivo en este trabajo no era entrar en esos debates, sino simplemente ofrecer una mínima información previa a los mismos $)^{84}$.

Una vez más -al igual que ocurría con los ataques de los realistas al formalismo de Langdell-, los españoles descubrimos que bastantes de esas críticas estarían mucho más justificadas en España; y tanto es así, que acaba por parecernos que en América no lo están en absoluto. Yo no pienso que esas críticas al sistema americano sean del todo absurdas, y algunas creo que son muy pertinentes. Lo que ocurre es que tanto mi visión como mi valoración de la enseñanza del Derecho en Estados Unidos están teñidas por una comparación, aunque sea casi inconsciente, con la situación española. Pero el suelo del que parten esos críticos no es el español, sino exclusivamente el americano; y desde ese contexto, tradicionalmente mucho más «sustantivo» y flexible que el nuestro, la enseñanza del Derecho dominante les parece mucho menos metodológica-interdisciplinar-crítica, etc. que a nosotros, y la critican. Como en tantas otras cosas, tampoco en la enseñanza del Derecho es oro todo lo que brilla en América. Pero, de momento, yo me daría por satisfecho si al menos lográramos pulir nuestra enseñanza hasta alcanzar un brillo semejante al americano. Aunque sólo fuera el pálido brillo de una bisutería informal diseñada para vestir con tejanos.

${ }^{84} \mathrm{He}$ aquí un puñado de esas críticas: el divorcio existente entre docencia e investigación; la orientación profesional de las facultades como fábrica de abogados para el mundo de los grandes negocios; la marginación en el curriculum de las materias más «políticas» o críticas frente a la centralidad de las que reproducen y legitiman el modelo existente en norteamérica; el apoliticismo tecnocrático de la concepción dominante sobre lo que es «pensar como un jurista» (o el «neoformalismo» disfrazado de argumentos de «policy» estandarizados y acríticamente asumidos, que ocultan la raíz político-moral del discurso jurídico); la precariedad de la «enseñanza clínica»; el «nivel intermedio» de la enseñanza, que ni forma buenos técnicos para el ejercicio ni buenos juristas con una sólida formación teórica; diversos defectos del sistema meritocrático de admisión de estudiantes; la timidez en la aplicación de políticas de «acción afirmativa» en favor de las minorías raciales; el ambiente emocional represivo, jerarquizado y competitivo que se crea en las aulas... 
DOXA-12 (1992) 